\title{
A review of the current state of the art of physiologically-based tests for measuring human dermal in vitro bioavailability of polycyclic aromatic hydrocarbons (PAH) in soil
}

\author{
Darren J. Beriro ${ }^{\mathrm{a}}$, Mark R. Cave ${ }^{\mathrm{a} *}$, Joanna Wragg ${ }^{\mathrm{a}}$, Russell Thomas ${ }^{\mathrm{b}}$, Gareth Wills ${ }^{\mathrm{b}}$, Frank Evans ${ }^{\mathrm{c}}$ \\ ${ }^{a}$ British Geological Survey, Keyworth, Nottingham, NG12 5GG, UK. \\ ${ }^{b}$ Parsons Brinckerhoff Queen Victoria House, Redland Hill, Bristol BS6 6US, UK \\ ${ }^{c}$ National Grid Property, National Grid House, Warwick Technology Park, Gallows Hill, Warwick, CV34 6DA, \\ $U K$ \\ *corresponding author mrca@bgs.ac.uk
}

\begin{abstract}
Polycyclic Aromatic Hydrocarbons are classed as Persistent Organic Pollutants, a large group of compounds that share similar characteristics. They are lipophilic, resistant to degradation in the environment and harmful to human and environmental health. Soil has been identified as the primary reservoir for Polycyclic Aromatic Hydrocarbons in the United Kingdom. This study reviews the literature associated with, or is relevant to, the measurement and modelling of dermal absorption of Polycyclic Aromatic Hydrocarbons from soils. The literature illustrates the use of in vivo, in vitro and in silico methods from a wide variety of scientific disciplines including occupational and environmental exposure, medical, pharmaceutical and cosmetic research and associated mathematical modelling. The review identifies a number of practical shortcomings which must be addressed if they are to be applied to high throughput laboratory analysis of contaminated soils for human health risk assessment.
\end{abstract}

Key words: PAH, soil, dermal absorption, bioavailability, contaminated land

\section{Introduction}

This is a review of recent literature associated with the human dermal bioavailability of Polycyclic Aromatic Hydrocarbons (PAH) in soil, in particular benzo[a]pyrene. PAH in soil can be naturally occurring (e.g. volcanic ash and its deposition and unburnt fossil fuels). However, the majority of PAH in soil are incidental bi-products of the combustion and incineration of carbonaceous material (Farrell-Jones, 2003). There are many hundreds of PAH but those that appear most commonly in the peer-reviewed literature are parent PAH that form the sixteen congeners defined by the United States Environmental Protection Agency (USEPA) as "Consent Decree” priority pollutants. PAHs are diverse in terms of their physico-chemical properties but generally an increase in molecular weight is 
proportional to decreasing aqueous solubility $\left(2.2 \mathrm{E}^{-05}\right.$ to 31 to $\left.\mathrm{mg} / \mathrm{l}\right)$, increasing log octanol-water partition coefficient (Log $\mathrm{K}_{\mathrm{ow}}$ from 3.37 to 6.75 ) and increasing log organic carbon partition coefficient (Log $\mathrm{K}_{\mathrm{oc}} 3.11$ to 6.58) (Environment Agency, 2008). Overall, PAHs are hydrophobic and lipophilic meaning they tend to preferentially partition in fats and oils and in non-aqueous phases. PAH are widely recorded in soil, typically at $\mathrm{mg} \mathrm{kg}^{-1}$ concentrations in urban soil and at lower concentrations in rural locations (Creaser et al., 2007; Vane et al., 2014). Some PAH are known and others are suspected to be carcinogenic and mutagenic to humans (Public Health England, 2008; U.S Environmental Protection Agency, 2013; International Agency for Research on Cancer, 2012). This assumption is mainly informed by a study on laboratory mice, which showed that $\mathrm{BaP}$ in a coal tar mixture fed to the animals in their food produced tumours (Culp et al., 1998). Many other studies have also recorded malignant tumours following dosing with individual congeners such as benzo[a]pyrene (see International Agency for Research on Cancer, 2012).

The bioavailability of contaminants in soil refers to the proportion of a contaminant that is released from soil and crosses a biological membrane. Bioavailability is generally considered as a process that is measured in a laboratory. A recent paper on the use of bioavailability in risk assessment discusses the concept in detail (Ortega-Calvo, 2015). The bioavailability of contaminants in soil is dependent on the physico-chemical properties of the contaminant source (including the soil vehicle), the exposure pathway and the receptor.

A large proportion of bioavailability research completed to date relates to the ingestion pathway and inorganic compounds. In response to ethical and cost issues associated with in vivo bioavailability estimates, in vitro tests have been developed that estimate bioaccessibility as a surrogate for bioavailability (in vitro review paper) Collins et al., 2015). Bioaccessibility is concerned with the release of contaminants from soil in vitro that are potentially available to cross a biological membrane (Wragg et al., 2011). The relationship between in vivo and in vitro tests is important because it helps to confirm whether the use of in vitro estimates is a suitable replacement for in vivo methods. Research has shown acceptable relationships between ingestion in vitro and in vivo data for As, Ca and $\mathrm{Pb}$ (Denys et al., 2012), leading to bioaccessibility tests being used in human health risk assessment of inorganic soil contaminants (Nathanail et al., 2007).

Bioavailability methods are less well developed for organic compounds and as yet none of the current bioaccessibility methods have been able to reliably replicate in vivo ingestion results (Collins et al., 2015; Ortega-Calvo et al., 2015). This is because of difficulties in accurately quantifying compounds that are known to be at least partly metabolised in vivo (Ounnas et al., 2009). Alternative approaches, such as analysing metabolites both in vivo and human biomonitoring studies, have been developed but there is still a lack evidence showing relationships between in vitro and in vivo data for the ingestion 
(or dermal and inhalation pathways) for organic compounds in soil (Ortega-Calvo et al., 2015). In silico studies are starting to appear in the literature that show that models are able to help explain some of the potential controls on bioaccessibility (Cave et al. 2015; Beriro, 2015). The physical structure of such models provide an opportunity to inform further research on the mechanisms that control the sorption of organic compounds to soil and their release once they are present in or on the receptor i.e. physico-chemical properties of the compounds and chemical properties of the soil (Cave et al. 2015).

The importance of the dermal absorption pathway is shown by Johnson and Kissel (1996) who found that 37 of 235 Superfund risk assessments conducted by the United States Environmental Protection Agency (USEPA) presented dermal pathway excess lifetime cancer risks higher than 1 in $10^{-4}$. There is also evidence that PAH, especially benzo[a]pyrene $(\mathrm{BaP})$, can cause skin cancers and adverse DNA interactions resulting in both localised and systemic effects (Public Health England, 2008; U.S Environmental Protection Agency, 2013; Nathanail et al.,, 2014).

The physiology of dermal uptake differs to that of the more extensively studied ingestion pathway. The latter involves the release and dissolution of chemicals from soil to digestive solutions prior to uptake across the lining of stomach or intestine (Cave et al., 2011). The dermal absorption of chemicals from soil is essentially a one-step process, where the chemical is released from the soil and absorbed into the skin via a thin oily superficial mantle. The assumption that release and absorption of chemicals from soil to skin is effectively simultaneous in addition for the potential for localised effects calls for the following operational definition of dermal bioavailability. The dermal bioavailability of organic compounds in soil is therefore defined as:

The proportion of the total concentration of an organic compound or compounds in soil that, following exposure, is absorbed into any part of the skin, that then may remain in situ or be potentially available for uptake by the blood compartment or tissues for storage, release and distribution to one or more target organs.

This operational definition is informed by explanations of dermal absorption provided in World Health Organisation Environmental Health Criteria 235, guidance by the USEPA and work edited by Roberts and Walters (Kielhorn et al.,, 2006; U.S Environmental Protection Agency, 2007). The definition has the benefit of being conservative since it assumes that any mass of chemical entering the skin has the potential to reach a site of action by residing in the skin and/or entering systemic circulation. It is acknowledged that the operational definition may not be universally accepted and may be restricted to the current work and any future applications. Unlike the ingestion pathway, the concept of bioaccessibility, i.e. the amount of a compound released in artificial human gastro- 
intestinal fluids, is not relevant to dermal bioavailability because there is no intermediate solution to solubilise the compounds of interest prior to uptake. Estimates of human dermal bioavailability will therefore be referred to as in vivo and in vitro to differentiate between human or animal based laboratory methods respectively. For the purpose of this study the primary measure of dermal bioavailability is the dermally absorbed fraction $\left(\mathrm{ABS}_{\mathrm{d}}\right)$ (Equation 1). $\mathrm{ABS}_{\mathrm{d}}$ is commonly expressed as a percentage by percent of absorbed dose applied (PADA), after Roy et al. (1998). ABS $_{d}$ and PADA are preferred because they are used in human health risk assessment for contaminants in soil (Environment Agency, 2009a).

$$
A B S_{d}=\frac{Q_{\text {soil }}}{T_{\text {soil }}}
$$

Where $Q_{\text {soil }}$ is the amount of compound absorbed into any part of the skin and $T_{\text {soil }}$ is the original total concentration in soil

Equation 1 - Percent absorbed of dose applied

The aim of this review is to synthesise current knowledge on the in vitro measurement and in silico modelling of the dermal absorption of PAH from soils. The objectives to be addressed to achieve this aim are:

i. Compile and review the literature associated with, or relevant to, the measurement and modelling of dermal absorption of PAH from soils with a greater focus on high molecular weight PAH i.e. $\geq 4$ to 5 ring congeners;

ii. To identify limitations in current work and highlight new emerging methodologies which, going forward, will assist in the development of a suitable physiologically based dermal bioavailability method for PAH in soil.

\section{Structure and function of the skin}

\subsection{Skin physiology}

The skin is the largest human organ. In a typical adult the skin weighs approximately $5 \%$ of total body mass and covers an area of $1.8 \mathrm{~m}^{2}$ (Pannatier et al., 1978). Skin functions include provision of a physical and chemical protective barrier, sensory perception (i.e. pressure, temperature and pain) and temperature regulation. The skin is comprised of three principal layers: 1) epidermis; 2) dermis; and 3) hypodermis. The innermost and thickest layer of the skin is the hypodermis (also known as the subcutaneous or superficial fascia). The hypodermis cells are specialised in accumulating and storing fats and are grouped together in lobules separated by connective tissues. The hypodermis acts as an anchor to the overlying layers. The next innermost layer is a $0.2-0.3 \mathrm{~cm}$ thick layer of tissue called the dermis which comprises a fibrous protein matrix of collagen, elastin and reticulum that is embedded in an amorphous colloidal ground substance. The dermis carries blood vessels, sensory 
nerves and lymphatic features and provides nutritional support for the outmost layer, the avascular epidermis. The stratum corneum is the outermost layer of the epidermis, consisting of dead cells.

The purpose of the stratum corneum is to form a barrier to protect underlying tissue from infection, dehydration, chemicals and mechanical stress.

\subsection{Dermal absorption}

The absorption of foreign substances into the skin takes place by dissolution and molecular diffusion through a composite, heterogeneous membrane, comprising of a two-phase protein-lipid interaction (Michaels et al., 1975). The dermal absorption pathways include:

i. Intracellular bulk pathways;

ii. Intercellular bulk pathways; and

iii. Shunt pathways (Chilcott, 2008).

A simplified representation of dermal absorption can be made by comparing the system to a physical structure of bricks and motor used to construct housing (Elias, 1983) (Figure 1). The principal route of dermal absorption is the intercellular pathway, which is enhanced and facilitated by stratum corneum lipids (Michaels et al., 1975; Elias, 1981; Grubauer et al,, 1987; Mao-Qiang et al., 1993; Bouwstra et al., 2001, 2003a; Ponec et al., 2003).

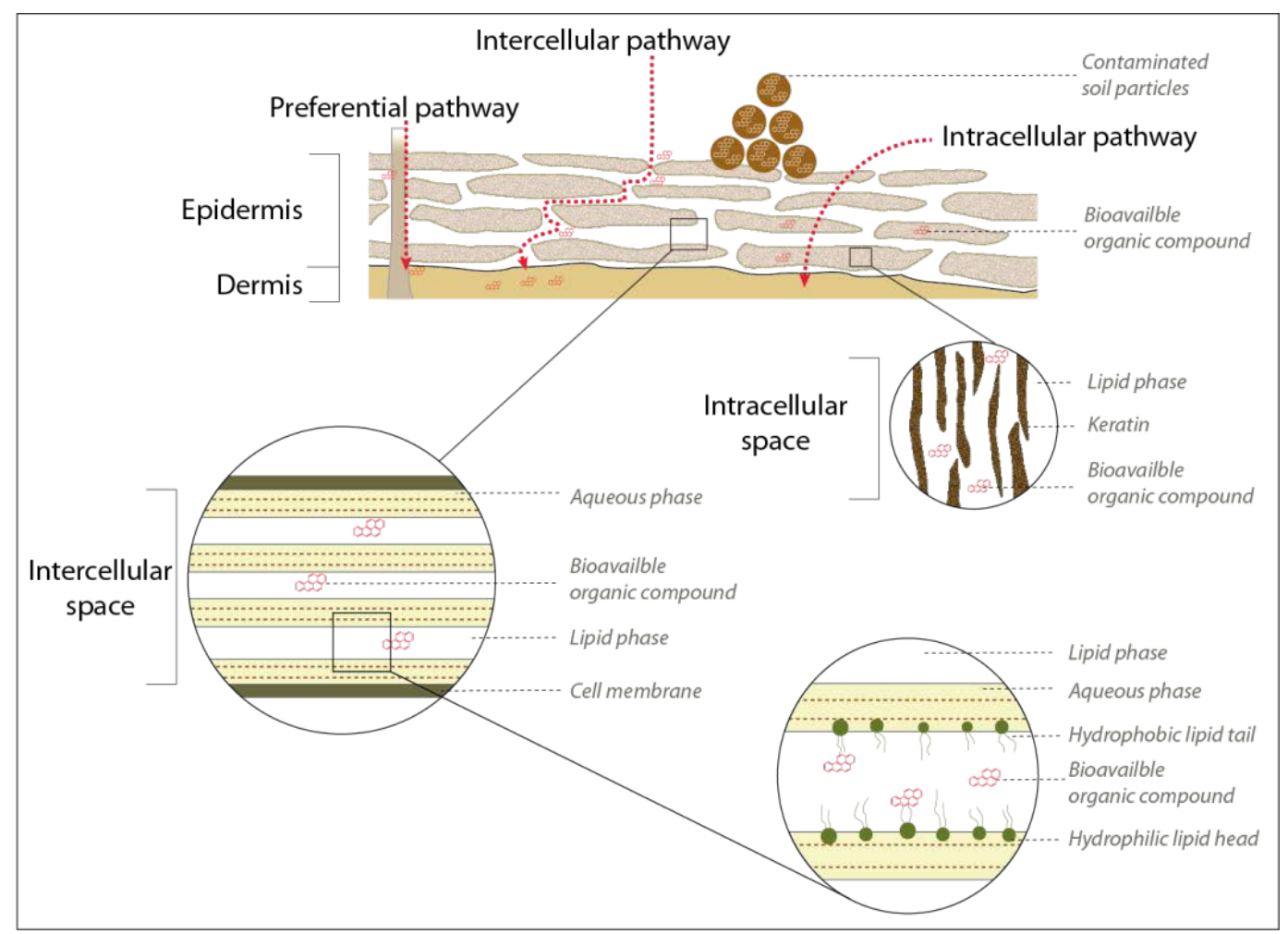

Figure 1 - Absorption pathways through the epidermis

The dermal bioavailability of a contaminant in soil depends of two factors: 1) the transfer of the compound from the vehicle i.e. permeation from the soil into the stratum corneum; and 2) penetration 
i.e. diffusion of PAH through the stratum corneum to underlying or adjacent cells (Pugh and Chilcott, 2008). Both processes need to occur in order for the compound to be absorbed into the skin and be available for systemic circulation. It is important to recognise that the presence of foreign compounds in the skin can lead to localised effects e.g. Langerhan cells may increase the likelihood of carcinogenesis due to the metabolisation of dermally absorbed PAH (Modi et al., 2012); similar observations of the genotoxicity of benzo[ $[a]$ pyrene have also been made for metablolisation by kerotinocytes (e.g. Brinkmann et al. 2013). It is because there is a potential for localised effects caused by PAH that bioavailability is defined in this review as a substance "absorbed into any part of the epidermis” rather than only the fraction subject to systemic circulation.

Dermal exposure to foreign substances may be under equilibrium or non-equilibrium conditions depending on the dose applied and the physico-chemical properties of the substance. When a substance is absorbed into the skin there is a maximum concentration that can be achieved which, relative to time, is referred to as the penetration rate or flux ( $\mathrm{J}$ ) and is expressed by $\mathrm{g} \mathrm{cm}^{-2} \mathrm{~h}^{-1}$ (Pugh and Chilcott, 2008). This exposure scenario is referred to as an infinite dose i.e. a theoretically unlimited supply of the substance. Should the penetration rate be limited by the amount of the substance available then the exposure scenario is referred to as a finite dose. The distinction between the infinite and finite dose is important for two reasons: 1) most bioavailability studies assume an infinite dose scenario in order to calculate kinetic parameters i.e. flux (J), permeability coefficient $\left(\mathrm{K}_{\mathrm{p}}\right)$ and diffusion coefficient (D); and 2), chronic exposure to soil assumes a finite dose scenario (Environment Agency, 2009b).

Steady state flux $\left(\mathrm{J}_{\mathrm{ss}}\right)$ is achieved after a lag phase $\left(\mathrm{T}_{\text {lag }}\right)$ has passed and is expressed graphically as the gradient of the penetration profile prior to any plateauing represented by the maximal concentration. The infinite dose across a membrane is expressed mathematically by Fick's First Law of diffusion (Equation 2 and Equation 3). The finite dose, referred to as diffusion within a membrane, is expressed mathematically by Fick’s Second Law of diffusion (Equation 4) (Crank, 1975).

$$
J=-D \frac{\delta C}{\delta x}
$$

Where $\mathrm{J}$ is the flux (rate of transfer per unit area), $\delta \mathrm{C}$ is the concentration gradient i.e. the change in concentration, $\delta \mathrm{x}$ is the distance travelled and $\mathrm{D}$ is the diffusion coefficient.

Equation 2 - Fick's First Law of diffusion

$$
J_{s s}=K p \cdot C o
$$

Where Jss is the steady state flux per unit area, Kp is the permeability coefficient expressed in distance and time for a given organic compound in soil and Co is the concentration of that compound in soil. In soil studies Kp becomes Ks/soil known as the skin/soil partition coefficient) (Roy and Singh, 2001). 


$$
\frac{\delta C}{\delta t}=D \frac{\delta^{2} C}{\delta x^{2}}
$$

Where the concentration of a compound within a membrane is derived by the differential mass balance and Fick’s First Law of diffusion assuming homogenous conditions with no net loss of the compound.

Equation 3 - Fick's Second Law of diffusion

The amount of a compound in soil penetrating the skin can also be expressed mathematically (Roberts and Walters, 2008) (Equation 5).

$$
Q=J_{S} A(T-\operatorname{lag})
$$

Where $Q$ is amount of compound absorbed, $J_{s}$ is the flux through the epidermis, $A$ is the area of application, lag is the effective lag time between application and absorption and $T$ is the exposure time. The time taken to reach steady state flux is approximately twice the lag time.

Equation 4 - Amount of compound dermally absorbed Physico-chemical properties of a penetrant compound affecting dermal bioavailability include molecular weight, solubility, charge and hydrogen bonding (Brain and Chilcott, 2008). The rule of thumb for the maximum size of molecule that can take advantage of these dermal absorption pathways is described by the 'rule of 500', which states that few molecules with a molecular weight above 500 Daltons are capable of diffusion through the skin (Bos and Meinardi, 2000). This rule may be broken by large long molecules such as heparin or DNA (Brain and Chilcott, 2008). The solubility of a chemical is principally determined by its partition coefficient. This is calculated as the proportion of the substance dissolved in an immiscible liquid mixture, typically octanol and water. The log of the ratio of the concentrations recorded in the two liquids is used to calculate the partition coefficient e.g. Log $K_{\text {ow }}$. Chemicals with a positive coefficient, between 1 and 3, are considered to be optimal for skin penetration resulting in entry to the systemic circulation, since higher or lower values will respectively: 1) remain in the lipid rich low moisture content stratum corneum; or 2) fail to access the stratum corneum (Brain and Chilcott, 2008). The stratum corneum carries a net negative charge as a result of proteins such as keratin with positively and negatively charged groups (Moody et al., 1995). This situation is suited to most organic molecules and therefore does not pose any barrier to permeation.

\section{Dermal bioavailability literature}

A review of the current literature on estimating the human dermal bioavailability of PAH in soil was conducted by searching the Scopus and Web of Science bibliographic databases using a range of relevant search terms. Further searches were made using Google and Google Scholar. Secondary 
references were examined in the articles found. The search continued until no new relevant references were identified. Studies were divided into four method groups: in vivo (including occupational exposure), in vitro, in silico and review. Each article identified was reviewed and the following information recorded: method group, year of publication, authors, lead institution, title, abstract, methods, source media, analytes, receptor, and species used in study and industry sector. Additional sources of supplementary information on human skin physiology, suppliers of laboratory bioavailability equipment and modelling software were also consulted and discussed where relevant.

A summary of the number of publications per year for each method group is given in (Figure 2). One hundred and thirty-four peer-reviewed journals articles and a small collection other material on or closely related to the dermal bioavailability of PAH from soil were reviewed. These articles covered the period between 1975 and 2015. The papers were divided into method group depending on the main function of the paper. The distribution of the peer-reviewed articles was broadly equal for in vivo $(\mathrm{n}=42)$ and in vitro $(\mathrm{n}=47)$ method groups over the period (Figure 2$)$. In silico $(\mathrm{n}=27)$ studies accounted for approximately half of the in vivo articles (Figure 4). Dermal bioavailability review papers $(n=18)$ appear in the literature from 2004 and cover the various aspects of dermal exposure assessment methods (Moody and Maibach, 2006; Van De Sandt et al., 2007; Frasch et al., 2014), compound group reviews (pesticides and organic flame retardants) (Tripp et al., 2007; Abdallah et al., 2015), metabolic pathways (Pannatier et al., 1978), contaminants in soil (Spalt et al,, 2009; Andersen et al., 2014), and in silico modelling (Moss et al.,, 2002a; Cronin and Schultz, 2003; Degim, 2006; Anissimov et al.,, 2013; Anissimov, 2014; Couto et al.,, 2014).

The articles reviewed were written by over 300 individual authors from various international academic, governmental and non-government organisations. Where the literature search results permitted, preference for detailed review was given to articles on the dermal bioavailability of PAH in soil. Where such studies were not available other relevant literature was reviewed. Relevant literature was defined as studies on the human and animal exposure to pharmaceuticals and other chemicals. For example, many European studies based in silico quantitative structure activity relationships (QSAR) research on individual chemical compounds, relates to regulatory requirements imposed by the European Regulation on Registration, Evaluation, Authorisation and Restriction of Chemicals (REACH) (European Commission Council Regulation, 2007). 


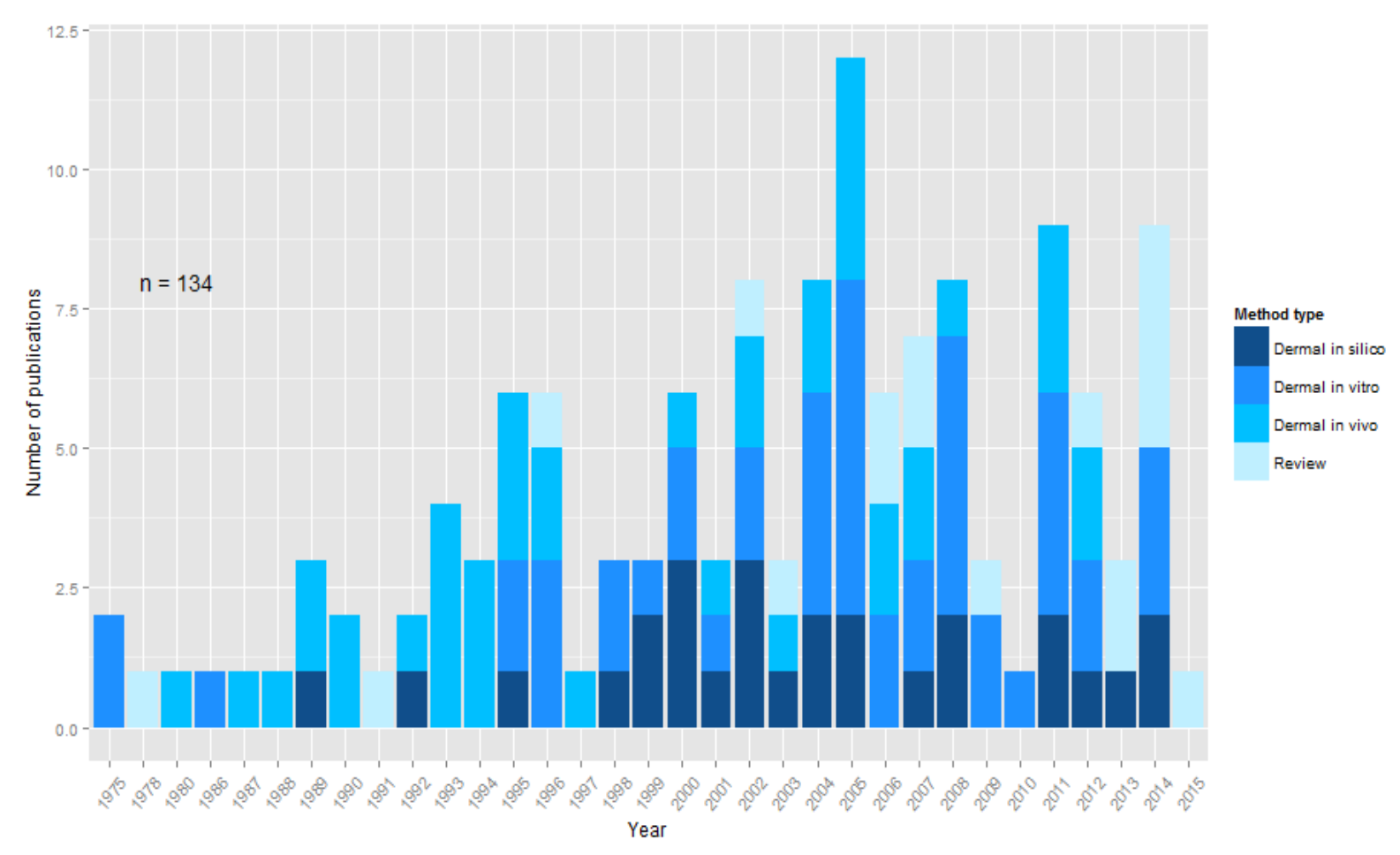

Figure 2 Summary of dermal bioavailability articles reviewed

Whilst this review is primarily aimed at in vitro testing methodologies for dermal bioavailability it is important to give an overview of the in vivo approaches as these supply data from physiologically and metabolically intact systems and are considered the "gold standard", from which base in vitro tests can be developed and compared. In vivo studies are, however, associated with strong ethical issues and there is an increasing movement towards the reduction of the use of animal testing e.g. (Keskin and Terzi, 2006) which will be emphasised in this review.

\subsection{In vivo dermal bioavailability}

\subsubsection{Occupational human exposure}

Occupational exposure to materials containing high concentrations of PAH has been described in a number of publications (Tsai, et al., 2001; Vaananen et al., 2005; Christopher et al., 2011; Kriech et al., 2011; Osborn et al., 2011b; Smith et al., 2011; McClean et al., 2012; Serdar et al., 2012; Fent et al., 2014; Kamal et al., 2014). Skin exposure is commonly measured using a wipe soaked in corn oil (Moody and Maibach, 2006) followed by extraction and quantification of the PAH content (Vaananen et al., 2005; Christopher et al., 2011; Osborn et al., 2011b; Cavallari et al., 2012; McClean et al., 2012; Fent et al., 2014). Moody and Maibach (2006) suggest that hand wiping is not necessarily best practice as it can increase the absorption of the contaminant by the "wash-in effect". Some studies have used passive samplers, which are attached to operatives that act as a surrogate for skin exposure measurements (Vaananen et al., 2005; Olsen et al., 2011a; Osborn et al., 2011b; Cavallari et al., 
2012). The passive sampler described by Olsen (2011a) consists of a 5-layer passive organic dermal sampler. Vaananen et al. (2005) showed that the passive sampler method they used gave statistically indistinguishable results compared to skin wipes showing a strong correlation $(r=0.757, \mathrm{P}<0.001, \mathrm{~N}$ $=23$ for total PAH).

In a number of these studies the internal PAH dose was quantified by analysing the PAH metabolites in urine samples. Metabolites of hydroxylated PAH (pyrene, phenanthrene, naphthalene and fluorene) have been analysed by Turkall et al. (1994); Elovaara et al., (2006); McClean et al.,, (2012); Serdar et al., (2012); and, Choosong et al., 2014). Pliel et al. (2000) quantified exposure of marker compounds (e.g. naphthalene) in jet fuel using the exhaled air of military personal. More recently, studies have focused on using 3-OHBaP as a carcinogenic marker in urine of animals and humans (e.g. Heredia et al. 2013; Barbeau et al. 2015). Other researchers have measured PAH in urine using an Enzyme Linked Immunosorbent Assay (ELISA) kit which measures the total PAH content as phenanthrene equivalents (Smith et al., 2011; Fent et al., 2014). In addition to this, Serdara et al. (2012) used a different ELISA kit on urine samples to determine oxidative DNA damage by measuring urinary 8oxo-2'-deoxyguanosine which showed a four-fold increase during work periods and correlated well with PAH urine concentrations. In those studies where urine analysis has been carried out, increased exposure to PAH in the workplace was clearly identified but they also showed exposure to PAH outside the workplace, which also includes that obtained from smoking and food. Two very comprehensive meta-analysis studies conducted by Bosetti et al., (2007) and Rota et al., (2014) bring together data on respiratory and urinary cancer health outcomes from epidemiological investigations of occupational exposure to PAH. The results show that increases in exposure in these industries leads to increased relative risk of cancer. Whilst the occupations studied (e.g. firefighters and road surfacing workers, military personnel) cover a variety of industries, there is no specific mention of workers exposed to PAH contaminated soil.

Although these occupational studies show that exposure to PAH results in increased PAH in the systemic circulation of workers and that covering vulnerable skin areas with protective clothing reduces exposure (Serdar et al., 2012) they do not give a quantitative or even semi-quantitative breakdown of how much of the internal dose comes from dermal absorption. Whilst this is very important information which clearly identifies the need for measuring how much PAH from a soil sample ends up in the human body from the dermal absorption route, the actual scientific methods are not very helpful in designing a testing methodology which makes that measurement. The one piece of technology which will have relevance is the passive sampler (Vaananen et al., 2005; Olsen et al., 2011a; Osborn et al., 2011b; Cavallari et al., 2012) which is used to measure the skin exposure in the work environment. These devices have the potential for measuring the fraction of PAH in a soil which 
is available to be absorbed by the skin and is therefore a conservative estimate of that which will actually absorbed.

\subsubsection{Animal exposure}

There are many in vivo studies on dermal bioavailability reported in the literature which are outside the scope of this review. The in vivo animal studies which relate specifically to PAH dermal bioavailability from soils have used monkeys, rats and guinea pigs (Yang et al., 1989; Wester et al., 1990; Turkall et al., 1994; Kadry et al., 1995; Moody et al., 1995; Roy et al., 1998a). These tests take the general form of applying the test chemical to a designated area of skin in an appropriate vehicle (for the purposes of this review this is soil). Body fluids, tissues, or excreta are collected at predefined intervals, and the quantity of chemical and /or metabolite is measured using a suitable analytical procedure. Finally at the end of the experiment the animal is sacrificed and the distribution of the test chemical between different body parts can be determined. The specific difficulty with soil is that it has to be held in place on the animal skin with a covering material which can lead to variability in skin contact area during the trial. For PAH, the additional difficulty is that the original compounds are metabolised as they go through the skin and enter systemic circulation and therefore both the original compound and the metabolites need to be analysed in the body fluids, tissues or excreta to get a true picture of its fate in the animal host. The in vivo studies for PAH in soil have overcome this problem by using soils spiked with radiolabelled PAH, following the distribution of the radioactive label in the host animal. The monkey study of Wester et al. (1990) used a less invasive approach, in which the ratio of radiolabelled $\mathrm{BaP}$ found in the urine of the monkey after application of the BAP spiked soil to the skin and the amount $\mathrm{BaP}$ found in the urine after intravenous injection of pure radiolabelled BaP in propylene glycol solution was calculated.

\subsection{In vitro dermal bioavailability methods}

Both the Organisation for Economic Co-operation and Development (OECD) (OECD, 2004) and United States Environmental Protection Agency (USEPA) (U.S Environmental Protection Agency, 2007) have set out guidelines for the in vitro determination of skin absorption which have also been or recognised by the World Health Organisation in Environmental Health Criteria 235 (Kielhorn et al., 2006).

\subsubsection{Diffusion Cell Design and operation}

The OECD guidelines state "A diffusion cell consists of a donor chamber and a receptor chamber between which the skin is positioned. The cell should provide a good seal around the skin, enable easy sampling and good mixing of the receptor solution in contact with the underside of the skin, and good temperature control of the cell and its contents. Static and flow-through diffusion cells are both acceptable”. The two most popular designs are the Franz static diffusion cell (Franz, 1975) and the 
Bronaugh flow through cell (Bronaugh and Stewart, 1984) (Figure 3). The OECD recommends maintaining a temperature of $37^{\circ} \mathrm{C}$ whereas the USEPA states $32{ }^{\circ} \mathrm{C}$. Both guidelines suggest that for lipophilic compounds that the receptor fluid should contain solvent mixtures (e.g. polyethylene glycol, olelyl ether, Bovine Serum Albumin (BSA)) to ensure the receptor is not rate limiting in the permeation step due to limited solubility. Both guidelines suggest the use of radiolabelled test materials to ensure the fate of the material through the cell can be traced and provide complete mass balance. Further information on sample loading, experiment sampling times are also given.

Schreiber et al. (2005) points out that European chemical policy in general, and the REACH initiative in particular, will increase the number of chemical substances for toxicological evaluation by several orders of magnitude. The need for high throughput measurements for dermal bioavailability has lead the redesign of the traditional Franz and Bronaugh diffusion cells as well as the development of new approaches to dermal bioavailability measurements.

A.

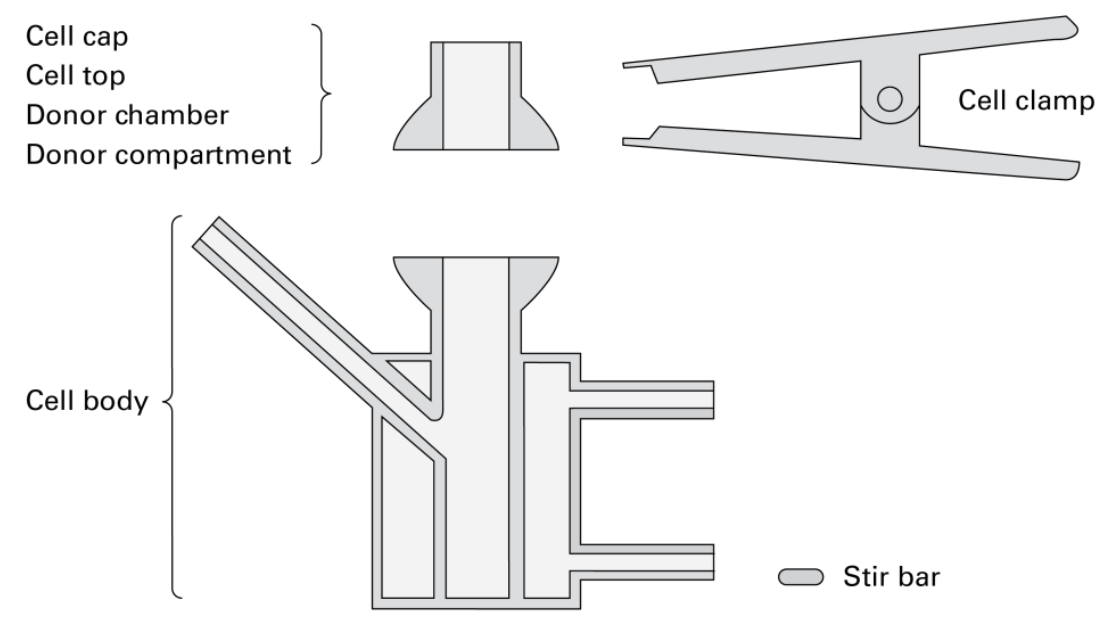

B. 


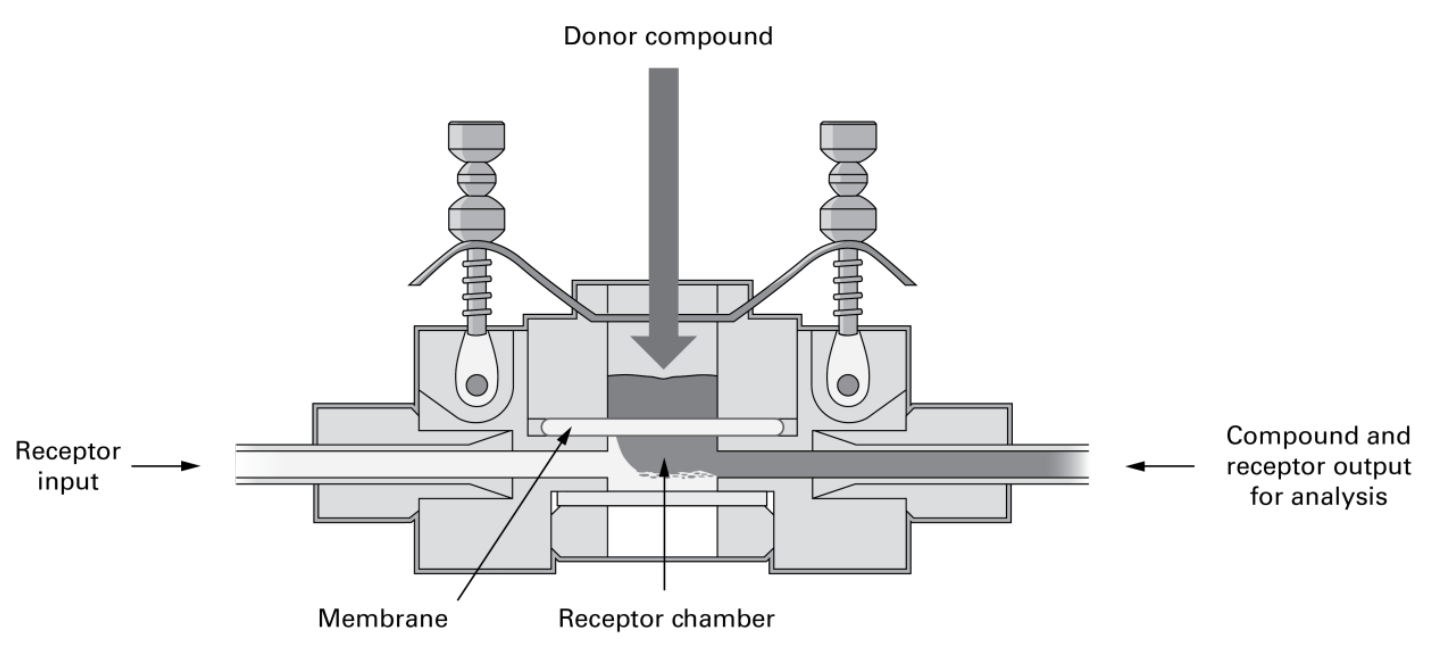

Figure 3 - Schematic diagrams of a typical Franz diffusion cell (a) and a Bronaugh diffusion cell (b)

\subsubsection{Multi-plate systems}

Jacques et al., (2010) essentially miniaturised the Franz static cell design. They used $28 \mathrm{~mm}$ diameter discs of pig ear skin placed dermal side down in polycarbonate Transwell ${ }^{\circledR}$ inserts (28 mm inner diameter, with a $23 \mathrm{~mm}$ diameter and $8 \mu \mathrm{m}$ pore size filter by Corning Life Sciences, Avon, France) placed in a 6 position well plate prefilled with $1.5 \mathrm{ml}$ culture medium at $37{ }^{\circ} \mathrm{C}$ in a $5 \% \mathrm{CO}_{2}$ air incubator. Using this approach they were able to carry out 6 diffusion cell experiments in parallel. Sinko et al. (2012) have developed this further by modifying a 96 well Parallel Artificial Membrane Permeability Assay (PAMPA) (Figure 4) that had already been used for estimating passive gastrointestinal absorption and blood-brain barrier permeability. In a follow up study, Karadzovska and Riviere (2013b) used the PAMPA methodology to compare the performance of synthetic skin membranes to porcine skin on a variety of organic compounds. The advantages of the cell array approach are that the plates are inexpensive and disposable and have the ability to carry out many tests simultaneously with the potential to automate dosing and sampling procedures. However, these cell arrays are made out of plastic which could provide PAH sorption sites. Whilst Jacques et al.(2010) reports that $<3 \%$ of the radiolabelled BaP used in their study was absorbed to the plate walls, Karadzovska and Riviere (2013b) do not report any losses of the target compounds to the well plates. Miki et al., (2015) have developed a high throughput PAMPA screening system for drug absorption into human skin with a copolymer containing poly(dimethylsiloxane) (PDMS) and poly(ethylene glycol) (PEG) supported on a membrane filter. This has been used successfully on both hydrophilic and lipophilic compounds (log Kow up to 3.86). For highly lipophilic PAHs such as BaP membrane testing may be required to ensure optimum performance. 


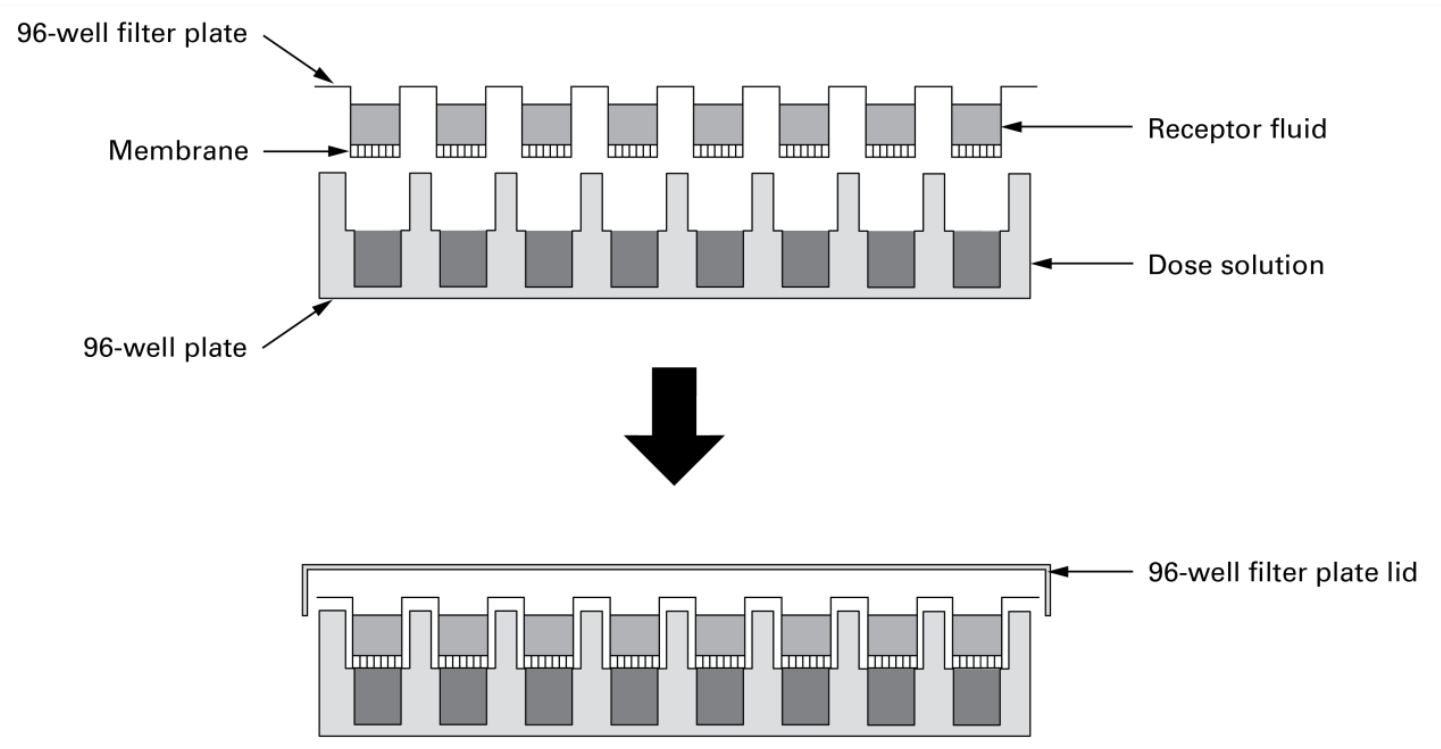

Figure 4 - Schematic of a multi-plate system for estimating in vitro dermal bioavailability

\subsubsection{Fibre Arrays}

A completely different approach to dermal bioavailability measurements has been reported in a number of studies (Riviere et al., 2007; Baynes et al., 2008; Karadzovska and Riviere, 2013a). The method uses a membrane-coated fibre (MCF) array to derive sorption data which is combined with regression modelling. A silica fibre is coated with absorbing media; these are used as a routine method of extracting and pre-concentrating target organic compounds from a variety of sample matrices prior to chemical analysis and are commercially available products.

The MCF array approach for skin permeability prediction is based on the similarity in the diffusion mechanisms of the MCF membrane and the stratum corneum of the skin. Several types of molecular interactions have been identified to be the primary factors in skin absorption: lipophilicity; hydrogen bonding and polarizable $\mathrm{p}^{*}$-electron interactions (Moss et al., 2002b). These molecular interactions are simulated with number of MCFs that reflect the different physico-chemical properties of the compounds under test. A set of 'training' compounds is used to measure the relative dermal bioavailability for a particular vehicle (this could be soil, although soil has not been tested) and the stratum corneum using a conventional diffusion cell. At the same time, sorption data are derived for the same compound and vehicle using a MCF array. A predictive model is established via multiple linear regression modelling using the MCF partition coefficients as the predictor variables and the dermal bioavailability as measured by the diffusion cell as the dependant variable.

The dermal bioavailability of new compounds can be predicted by measuring the partition coefficients of these compounds in the vehicle using the MCF membranes. The main advantage of this approach is that the MCF measurements can be automated and would be a relatively straight forward high 
throughput method to be implemented in a standard testing laboratory. As an example, a study used the MCF approach to evaluate the use of synthetic skins in a 96 well PAMPA assay compared to porcine skin in a convention diffusion cell (Karadzovska and Riviere 2013b). Three MCFs, polydimethylsiloxane (PDMS), polyacrylate (PA) and CarboWax (Wax), were used to determine the partition coefficients for a set of calibration compounds. Correlations between the MCF partition coefficients and the diffusion cell dermal bioavailability measurements were investigated and it was concluded that the Strat-M ${ }^{\mathrm{TM}}$ synthetic skin was a good analogue of ex vivo porcine skin.

\subsubsection{Passive samplers}

Passive samplers are primarily designed to simulate the amount of contaminant deposited on a skin surface, usually from occupational exposure. The samplers are placed on the skin at various locations around the human body and after exposure the target compounds are extracted from the sampler and analysed. Two studies of occupational exposure to PAH, one on road pavers from and one on operatives from a gasworks site, simply used proprietary polypropylene filters as passive samplers (Dor et al., 2000; Vaananen et al., 2005). Vaananen et al.(2005) compared the performance of passive samplers to skin washes and found equivalent performance. Olsen et al. (2011b) developed a more sophisticated 5 layer design. The 5-layers, from outside in, consisted of polypropylene, polyurethane foam, C-18 solid-phase extraction disk, ethylene tetrafluoroethylene, and an activated carbon cloth which they went on to use in further occupational studies on PAH exposure (Osborn et al., 2011a). The layers were enclosed in aluminum foil and placed in a muslin envelope that had a $40.0 \mathrm{~mm}$ diameter opening. The passive samplers measures how much of the contaminant under study is deposited onto the skin surface and not how much is absorbed into the skin.

In a study of PAH contaminated soil, Hu and Aitken (2012) used a passive sampler to measure the amount of PAH released from a soil when placed on a C-18 extraction disk, at three different temperatures $\left(20{ }^{\circ} \mathrm{C}, 30{ }^{\circ} \mathrm{C}\right.$ and $\left.40{ }^{\circ} \mathrm{C}\right)$, four soil moisture concentrations of $(2 \%, 8 \%, 20 \%$ and $40 \%)$ and seven soil loadings (5-100 mg dry soil $\mathrm{cm}^{-2}$ ) over periods of 6 days. Whilst this is not a measure of dermal bioavailability it measures the amount of PAH that is availble for absorption from the skin. This could be a useful measurement when working with soils since it provides measure of the availability of the PAH from the soil which in the first instance can be regarded as a conservative estimate of that which can be demally absorbed. The study showed that after bioremediation PAH desorption from the soil was completely eliminated.

\subsubsection{In vitro membrane types used}

The choice of skin to use as the diffusion membrane is of high importance. Both USEPA and OECD guidelines specify that human skin is the "gold standard" (Organisation for Economic Co-operation and Development, 2004; U.S Environmental Protection Agency, 2007). Human skin is, however, not 
always easily available and a number of studies have used alternative animal skins. In studies where PAH dermal bioavailability, with and without soil have been studied (Wester et al.,, 1990; Moody et al., 1995; Roy et al,, 1998b; Roy and Singh, 2001; Moody et al., 2007; Moody et al., 2009; Moody et al., 2011), pig (Jacques et al., 2010), rat (Yang et al., 1989; Moody et al., 1995; Roy et al., 1998a) and guinea pig skin (Moody et al., 1995) have been used.

An increasing trend is to move away from ex vivo animal skin to reconstructed human epidermis (RHE) skin substitutes (Netzlaff et al., 2005; Schreiber et al., 2005; Schaefer-Korting et al., 2008). A number of synthetic skin products are commercially available and have been evaluated in the literature. EPISKIN ${ }^{\circledR}$, EpiDerm ${ }^{\mathrm{TM}}$ and SkinEthic ${ }^{\circledR}$, were tested against ex vivo human and pig skin to evaluate their suitability for in vitro dermal availability measurements. The substances used were tested under both infinite-dose and finite dose conditions in ten laboratories and under strictly controlled conditions. The data were subjected to independent statistical analyses. In general, permeation of the synthetic skins exceeded that of human and pig skin, yet the ranking of substance permeation through the three tested RHE models and the pig skin reflected the permeation through human epidermis. Whilst PAH were not tested, three compounds with $\log \mathrm{K}_{\mathrm{oc}}$ of 3.5 to 6.8 and a molecular weight (MW) of 288-875, similar to commonly found PAH, were studied.

Two recent studies have shown very promising comparative performance between artificial skin and human and pig skin. Karadzovska and Riviere (2013b) have studied three artificial membranes isopropyl myristate (IPM), certramides and a new synthetic skin (Strat-M ${ }^{\mathrm{TM}}$ ) using PAMPA for skin (Sinko et al.,, 2012). Although the compounds they used were not PAH, they used sodium diclofenac which has similar $\log \mathrm{K}_{\mathrm{oc}}$ and MW (4.5 and 318 respectively) to PAH found in soil samples. Resultant absorption data was compared to porcine skin diffusion cell data. A correlation between membrane retention and the amount remaining in skin had $\mathrm{r}^{2}$ values of 0.73 (Strat-M $\mathrm{M}^{\mathrm{TM}}$ ), 0.67 (certramides), and 0.67 (IPM). Uchida et al. (2015) confirmed the suitability of Strat-M ${ }^{\mathrm{TM}}$ as a replacement for animal skin. They used 13 chemical compounds with molecular MW of 152-289 and log Koc of 0.9 to 3.5 . The performance of Strat-M ${ }^{\mathrm{TM}}$, human skin, or rat skin in a Franz-type diffusion cell was compared. The diffusion and partition parameters of chemicals in Strat-M $\mathrm{M}^{\mathrm{TM}}$ were similar to those in the human and rat skins. They concluded that Strat-M $\mathrm{M}^{\mathrm{TM}}$ could be used as an alternative to animal or human skin in dermal bioavailability studies.

\subsubsection{Key in vitro dermal bioavailability studies}

Most of the work on dermal bioavailability is directed at occupational exposure of potentially harmful substances including pharmaceuticals, jet fuel and cosmetics for pure substances. There has been recognition, however, that chemicals are rarely applied to the skin in their pure form and that the dosing vehicle as well as the presence of more than one contaminant, especially when in a mixture, 
can have significant effects on the way in which the target chemical is absorbed (Riviere and Brooks, 2005; Karadzovska et al., 2013b; Riviere et al, 1999). Spalt et al., (2009) reviewed a large number of publications where the dosing vehicle is soil or sediment for a variety of contaminants. The Spalt study presents a comprehensive review of a subset of dermal bioavailability studies for $\mathrm{PAH}$, where $\mathrm{BaP}$ is the most commonly reported congener, with a smaller number of studies focusing on naphthalene and phenanthrene. Key dermal bioavailability studies for PAH in soil are discussed with key points summarised in Table 1 (Yang et al,, 1989; Wester et al., 1990; Moody et al., 1995; Roy et al., 1998a; Roy et al., 1998b; Riviere et al., 1999; Roy and Singh, 2001; Abdel-Rahman et al., 2002; Moody et al., 2007; Moody et al., 2009; Jacques et al., 2010; Moody et al., 2011).

\section{Yang et al, (1989)}

Yang et al. (1989) used the same experimental in vitro set up used in Roy (1998) but instead used rat skin and compared their results to a parallel in vivo rat study. The study used a single air dried loam sample that was sieved to $<150 \mu \mathrm{m}$ and spiked with crude oil and tritiated BaP, although no ageing of the soil was carried out. The soil loadings were chosen to produce a monolayer of soil in both in vivo and in vitro studies. Within experimental error, the diffusion cell results agreed with the in vivo data and the dermal bioavailability of $\mathrm{BaP}$ from the crude oil alone was reduced by a factor of 4-5 when in the soil matrix. It appears that the in vitro data was derived from the concentration of $\mathrm{BaP}$ in the receptor solution only.

\section{Wester et al. (1990)}

The Wester et al.(1990) paper is important as the data reported here has been used in both the U.K and U.S as their generic values for BaP dermal absorption factors (CL:AIRE, 2013; Nathanail et al., 2014). The study measures the dermal bioavailability of BaP using an in vitro test with human skin and an in vivo test with rhesus monkeys. The study uses only one soil (26\% sand, $26 \%$ clay and $48 \%$ silt, no organic carbon content is given). The soil was spiked to $10 \mathrm{mg} \mathrm{kg}^{-1}$ with ${ }^{14} \mathrm{C}$ radiolabelled BaP. No ageing of the soil was carried out. The in vitro apparatus consisted of small flow through diffusion cells with a $1 \mathrm{~cm}^{2}$ membrane surface area and a receptor solution of human plasma pumped at $3.0 \mathrm{ml} \mathrm{h}^{-1}$. The in vivo study on rhesus monkeys used the same soil and measured the ratio of BaP found in urine after application of the soil to abdominal skin to the $\mathrm{BaP}$ in urine after an intravenous dose of BaP. The in vitro study found that, when applied in a soil matrix, $1.4 \pm 0.9 \%$ of the applied dose was absorbed into the skin with $0.01 \pm 0.004 \%$ in the plasma receptor fluid, whereas when radiolabelled $\mathrm{BaP}$ was applied directly to the skin in acetone solution $23.7 \pm 9.7 \%$ was absorbed into the skin and $0.09 \pm 0.06 \%$ in the receptor plasma. In the in vivo test, the percentage of applied dose absorbed for BaP in acetone was $51.0 \pm 22$ and in soil was $13.2 \pm 3.4$. Like the study of Roy et al. (1998), this shows that the skin itself is an important sink for absorbed PAH and should be included in the calculation of dermal bioavailability. The results also show that the soil matrix is important factor 
in reducing PAH dermal bioavailability (a factor of 17 times lower for the in vitro test and factor of 4 for the in vivo study).

\section{$\underline{\text { Riviere et al. (1999) }}$}

Riviere et al. measured the dermal absorption of marker compounds, including Naphthalene, in different Jet fuel mixtures using the in vitro isolated perfused porcine skin flap (IPPSF) method. This method is a self-contained system that mimics skin perfusion by maintaining vascular supply to the tissues using an artificial buffer solution. Further details of the method can be found in (Riviere et al., 1986). The study shows that aliphatic marker compounds are absorbed slower than Naphthalene. In addition, the study shows that the penetration of Naphthalene is deeper the aliphatic markers, resulting in lower concentrations recorded in the stratum corneum in comparison to other markers. The study explains that measurements of systemic circulation, i.e. concentrations in the purfusate, and local accumulation in the stratum corneum may be different depending on the properties of the substance under test. Another key finding was the absorption profiles differed between the fuel types tested - it was suggested that the fuel additive may be the cause. Unfortunately, Naphthalene was the only PAH under test, but the results suggest that the individual hydrocarbons demonstrate different absorption and penetration profiles depending on the mixture, supporting the notion that physico-chemical properties are important in understanding compound bioavailability in localised and systemic contexts.

\section{Roy et al. (1998) and Roy \& Singh (2001)}

The Roy et al. (1998) study was unique in that it used 9 naturally contaminated soils from manufactured gas plant sites. The soils were analysed for 18 target PAH but unfortunately the total concentration of the PAH in the soils was not reported and no other information on the mineral or organic carbon content of the soils was given. The soils were spiked with tritiated BaP and the dermal bioavailability was determined using Franz type diffusion cell with previously frozen human skin samples. The mass balance of the radiolabelled $\mathrm{BaP}$ in the diffusion cell receptor fluid, in the skin sample, on the skin surface and on the cell wall was determined. For all of the soils, less than $1 \%$ of the dose from tritiated $\mathrm{BaP}$ was found in the receptor fluid, ca. $1 \%$ in the skin and $>80 \%$ on the surface of the skin (from a skin wipe) and 1-3\% on the cell walls. A control experiment was carried out using PAH extracts from the soil without the soil matrix. When directly analysing the total target $\mathrm{PAH}$ in the receptor fluid the results showed a 2-3 order of magnitude reduction in PAH absorption compared soil extracts. The study had four main inconsistencies and problems: 1) the target PAH data for all nine soils was not presented; 2) the studies were carried out on freshly spiked soils; 3) a high concentration of $\mathrm{PAH}$ was used equivalent to an infinite dose rather than a finite dose encountered in PAH in soil exposure scenarios; and 4) the absorbed doses and contaminated flux data reported are for radiolabelled $\mathrm{BaP}$ not the naturally occurring PAH in the soils. Roy and Singh (2001) 
addressed the last two points using the same experimental set up but they used a single "field soil" sieved to $<150 \mu \mathrm{m}$ with an organic carbon content of $0.43 \%$. The soil was extracted with methylene chloride to remove unwanted organic matter prior to spiking with crude coke oven tar to give a $\mathrm{BaP}$ concentration of $65 \mathrm{mg} \mathrm{kg}^{-1}$ followed by aging at $20^{\circ} \mathrm{C}$ in the dark for three time steps: 1,45 and 100 days. The soils were also freshly spiked with tritiated BaP to check for the effect of ageing. The study looked at sample loading over the range of $1-10 \mathrm{mg} \mathrm{cm}^{-2}$ and showed that higher sample loading led to a reduction in percentage dose of $\mathrm{BaP}$ absorbed. This was assumed to be due to soil layering effects in which higher soil loadings lead to multiple layers of soil; where layers not in contact with the skin contribute less BaP. The experiment showed that the 110 days of aging reduced the dermal bioavailability by a factor of 2 compared to freshly spiked soil. The study also showed that the dermal flux of $\mathrm{BaP}$ from the crude coke oven tar was reduced by a factor of 10 when compared to the raw material to soil spiked with the tar. Again, it is unclear if the dermal bioavailability includes the amount of $\mathrm{BaP}$ in the skin as well as in the receptor fluid. 
Table 1 - Summary of key in vitro dermal bioavailability studies

\begin{tabular}{|c|c|c|c|c|c|c|c|c|}
\hline Experimental studies & PAH congeners & $\begin{array}{l}\text { Animal / skin } \\
\text { site }\end{array}$ & $\begin{array}{l}\text { Study } \\
\text { type }\end{array}$ & Soils & $\begin{array}{c}\text { Reduction } \\
\text { Factor in } \\
\text { absorption due } \\
\text { to soil matrix }\end{array}$ & Analytical method & Cell type & Receptor solution \\
\hline Yang et al. (1989) & Benzo[a]pyrene & Rat Back & $\begin{array}{l}\text { In vivo \& } \\
\text { in vitro }\end{array}$ & Yes & $4-5$ & $\begin{array}{l}\text { Radiometric analysis method } \\
\text { not specified }\end{array}$ & Franz diffusion cell & $\begin{array}{l}6 \% \text { Volpo-20 and } 0.01 \% \\
\text { thimerosal antibacterial }\end{array}$ \\
\hline Wester et al.(1990) & Benzo[a]pyrene & $\begin{array}{l}\text { Rhesus monkey, } \\
\text { human } \\
\text { Abdomen }\end{array}$ & $\begin{array}{l}\text { In vivo, in } \\
\text { vitro }\end{array}$ & Yes & $\begin{array}{l}17 \text { in vitro } \\
4 \text { in vivo }\end{array}$ & Liquid scintillation counting & $\begin{array}{l}\text { Flow thru diffusion } \\
\text { cell }\end{array}$ & Human plasma \\
\hline Turkall et al. (1994) & Naphthalene & Rat, Abdomen & In vivo & Yes & NR & Liquid scintillation counting & na & na \\
\hline Kadry et al.(1995) & Phenanthrene & Rat & In vivo & Yes & NS & Liquid scintillation counting & na & na \\
\hline Moody (1995) & Benzo[a]pyrene & $\begin{array}{l}\text { Guinea pig, rat, } \\
\text { human }\end{array}$ & $\begin{array}{l}\text { In vivo \& } \\
\text { in vitro }\end{array}$ & No & na & Liquid scintillation counting & $\begin{array}{l}\text { Teflon Bronaugh } \\
\text { diffusion cells }\end{array}$ & $\begin{array}{l}\text { Hanks Balanced salt solution, } \\
10 \% \text { fetal bovine serum }\end{array}$ \\
\hline Roy (1998) & $60 \mathrm{PAH}$ & Rat & In vitro & No & na & GC FID, GC MS & Franz diffusion cell & $\begin{array}{l}\text { Aqueous } 6 \% \text { polyethylene } \\
\text { glycol, } 20 \% \text { oleyl ether }\end{array}$ \\
\hline Roy et al. (1998) & Benzo[a]pyrene & $\begin{array}{l}\text { Human } \\
\text { Abdomen }\end{array}$ & In vitro & Yes & $100-1000$ & $\begin{array}{l}\text { GC MS selected ion mode \& } \\
\text { Liquid scintillation counting }\end{array}$ & Franz diffusion cell & $\begin{array}{l}\text { Aqueous } 6 \% \text { polyethylene } \\
\text { glycol, } 20 \% \text { oleyl ether, } 0.01 \% \\
\text { antibacterial agent }\end{array}$ \\
\hline Riveire et al. (1999) & Napthalene & Porcine & In vitro & No & na & Liquid scintillation counting & $\begin{array}{l}\text { The isolated perfused } \\
\text { porcine skin flap } \\
\text { (IPPSF) }\end{array}$ & Perfusate \\
\hline Roy and Singh (2001) & Benzo $[a]$ pyrene & $\begin{array}{l}\text { Human } \\
\text { Abdomen }\end{array}$ & In vitro & Yes & 10 & Liquid scintillation counting & Franz diffusion cell & $\begin{array}{l}\text { Aqueous } 6 \% \text { polyethylene } \\
\text { glycol, } 20 \% \text { oleyl ether }\end{array}$ \\
\hline $\begin{array}{l}\text { Abdel-Rahman et al. } \\
\text { (2002) }\end{array}$ & Benzo[a]pyrene & Pig, Abdomen & In vitro & Yes & $\begin{array}{l}\text { Sandy soil } 21 \\
\text { Clay soil } 42\end{array}$ & $\begin{array}{l}\text { Radiometric analysis method } \\
\text { not specified }\end{array}$ & $\begin{array}{l}\text { Teflon flow through } \\
\text { diffusion cells }\end{array}$ & $\begin{array}{l}\text { Hanks Balanced salt solution, } \\
10 \% \text { fetal bovine serum }\end{array}$ \\
\hline Moody (2007) & Benzo $[a]$ pyrene & Human, breast & In vitro & Yes & 3 & Liquid scintillation counting & $\begin{array}{l}\text { Teflon Bronaugh } \\
\text { diffusion cells }\end{array}$ & $\begin{array}{l}\text { Hanks Balanced salt solution, } \\
10 \% \text { fetal bovine serum }\end{array}$ \\
\hline Moody (2011) & 16 US EPA & Human, breast & In vitro & Yes & NR & $\begin{array}{l}\text { HPLC with photodiode } \\
\text { array detector }\end{array}$ & $\begin{array}{l}\text { Teflon Bronaugh } \\
\text { diffusion cells }\end{array}$ & $\begin{array}{l}\text { Hanks Balanced salt solution, } \\
10 \% \text { fetal bovine serum }\end{array}$ \\
\hline Jacques et al. (2010) & Benzo[a]pyrene & Pig, Ear & In vitro & No & na & $\begin{array}{l}\text { Liquid scintillation counting, } \\
\text { ion trap MS, NMR }\end{array}$ & $\begin{array}{l}\text { Transwell system } \\
\text { static diffusion }\end{array}$ & $\begin{array}{l}\text { Dulbecco's Eagle Modified } \\
\text { Medium (DMEM), antibacterial }\end{array}$ \\
\hline
\end{tabular}

NOTES: na Not applicable; NR Not recorded; NS Not significant 
Abdel-Rahman (2002)

Abdel-Rahman (2002)_recognised the limitations of in vivo studies carried out by Turkall et al., (1994) and Kadry (1995). The same soils (a sandy soil: 90\% sand, $2 \%$ clay, 4.4\% organic matter; a clay soil: $50 \%$ sand, $22 \%$ clay, $1.6 \%$ organic matter) were autoclaved and deionised water added to achieve a moisture content of $11 \%$. The soils were spiked with tritium labelled BaP and aged by sealing in glass vials and storing in the dark for three months. The in vitro study used fresh pig skin mounted in a diffusion flow through cell. For pure BaP and spiked soils less than $1 \%$ of the total dose was found in the receptor fluid. For pure compound ca. 75\% of the dose was found in the skin. With freshly spiked sandy and clay soil, $8.5 \%$ and 3.5\% respectively, and aged soil, 3.7\% and 1.8\% respectively, were found in the skin. Clearly the aging reduces the dermal bioavailability of PAH. Unlike the Turkall et al.(1994) and Kadry (1995) studies, the sandy soil with higher organic matter had higher dermal bioavailability. This is probably due to the autoclaving step used in soil preparation which may have broken down the organic matter in the soil.

\section{Moody et al. (2007)}

Moody et al. (2007) from Health Canada carried out a very similar study to the in vitro testing of human skin described by Wester et al. (1990). In this case they used a single soil described as a “commercial gardening soil” (no information on mineral or organic carbon content was given), which was air dried, ground and sieved to $<710 \mu \mathrm{m}$. Sub-samples (32 mg) of the soil were spiked with ${ }^{14} \mathrm{C}$ radiolabelled $\mathrm{BaP}$ with no ageing of the soil being carried out. The study used a Bronaugh Type flow through cell with a receptor solution consisting of Hanks buffer salt solution containing 4\% BSA using female breast tissue as the skin membrane. Experiments were carried out over two time periods of 24 and $42 \mathrm{~h}$. The percentage of the applied dose of BaP absorbed (including both in the skin and in the receptor solution) for the 24 h study was $14.8 \pm 6.17 \%(n=6)$ in the soil matrix and $56.4 \pm 10.49$ ( $n=6)$ after direct application to the skin, and for the $42 \mathrm{~h}$ study they were $15.8 \pm 8.3(n=4)$ and 49.7 \pm 9.35 ( $n=5$ ) respectively. Whilst there was no significant difference between time periods the data show a clear reduction in dermal bioavailability when the $\mathrm{BaP}$ is applied in a soil matrix compared to direct application to the skin (a factor of ca. 3.5). The authors point out that the value for the absorbed dose from the spiked soil obtained in this study is in close agreement (i.e. $13.2 \pm 3.4$ ) with the in vivo study of Wester et al. (1990). They note that the Wester study used an occluded (covered) application of soil in the in vivo but their study did not and that they may not be comparable. In addition to this, they were using a different soil sample and sample loading which may have very different BaP release characteristics from the Wester study. The agreement is therefore more likely to be down to chance. Moody discusses soil loading, particle size organic matter content of soils and their possible effects on dermal bioavailability but none of these were investigated in this study. 


\section{Moody et al.(2011)}

The Moody et al.(2011) group from Health Canada address some important practical points in this study. All of the studies in Table 1 rely on the use of radiolabelled PAH to study the fate of the PAH from the soil, in and through the skin sample and finally into the receptor solution. In order to do this the soil sample has to be spiked with radiolabelled PAH. If the dermal bioavailability of a series of real-world contaminated soils is required, the PAH will not be radiolabelled, and the only way to quantify the dermal bioavailability will be through specific analysis of each PAH using standard analytical techniques for organics (e.g. GC-MS or HPLC).

Moody et al. (2011) used a "by difference" method to quantify the dermal bioavailability of realworld PAH that required the analysis of two media - the original contaminated soil and an analysis of the same soil after $24 \mathrm{~h}$ of exposure in a diffusion cell (the same apparatus and operating conditions as Moody et al. (2007)). The applied soil remaining on the membrane was removed using a soap-wash. The difference between the amounts of PAH in the original soil and that found in the soap wash expressed as a percentage of the mass in the original sample, providing a PADA value. Using this approach, it is neither necessary to analyse the amount of PAH in the skin membrane nor the amount of PAH in the receptor solution. The soil they used for this was from a coal-tar contaminated site in Canada and contained $255 \mathrm{mg} \mathrm{kg}^{-1}$ of the USEPA $16 \mathrm{PAH}$, where individual compounds ranged from 0.9 to $56 \mathrm{mg} \mathrm{kg}^{-1}$. The problem encountered with this approach was that the amount of soil used in the test (32 mg) is low causing difficulties in detecting the low concentrations of PAH in the soap extracts with the HPLC and UV-vis detector system used for the study. Percentage dermal bioavailability data for only five of the 16 PAH originally analysed was reported: phenanthrene (60.8\%); fluoranthene (49.4\%); pyrene (48.7\%); 1, 2-benzanthracene (26.4\%); and chrysene (33.5\%). These PAH showed an average reduction of 2 in their percentage dermal bioavailability compared to equivalent tests without a soil matrix and a linearly decreasing trend in dermal bioavailability with increasing octanol/water partition coefficients (Figure 5). It should be remembered that the study uses a single soil and that findings show $\mathrm{K}_{\mathrm{oc}}$ has a larger effect on dermal bioavailability of PAH in soil compared to the pure compounds, but also that when $\log K_{\mathrm{oc}}<4.5$, the effect of the soil matrix in suppressing dermal bioavailability is not significant. 


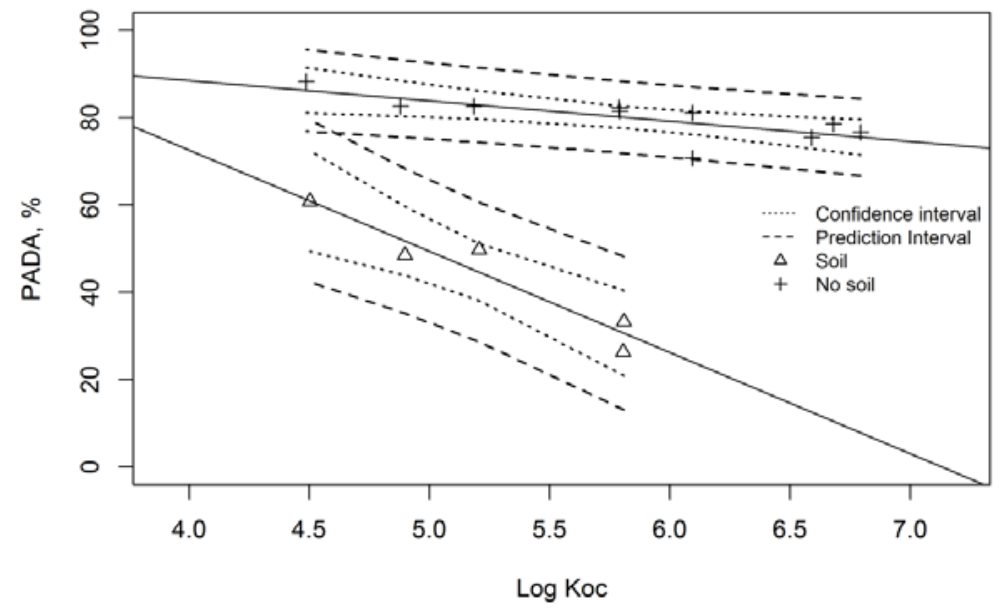

Figure 5 - Comparison of dermal bioavailability of PAH with and without a soil matrix (Moody 2011)

In addition to the studies listed in Table 1 which relate to dermal bioavailability of PAH contaminated soils, five other papers have been included which have studied direct dermal bioavailability of PAH compounds applied directly to skin in their pure form. These papers illustrate a number of important points that should be considered when developing a dermal bioavailability test for PAH contaminated soils. Three papers discuss the effect of skin type and skin preparation on dermal bioavailability. Moody et al. (2007) uses a similar in vitro flow through diffusion cell to Moody et al. (1995) measuring the dermal bioavailability of radiolabelled $\mathrm{BaP}$ combining together the $\mathrm{BaP}$ found in the receptor solution and absorbed in the skin. They compared rat, guinea pig and three types of human skin, all freshly prepared. They found percentage dermal bioavailability values ranging from 95\% down to $23 \%$ under the same experimental conditions. In particular there was a significant difference from the skin of a 50 year old human ( $43 \pm 8.7 \%$ ) and that of a 32 year old human ( $23 \pm 5.3 \%$ ) clearly showing that skin age is an important parameter. In the same study they also carried out in vivo tests on the rat and guinea pig and found that for the rat the in vitro test (95 $\pm 9.6 \%$ ) over-estimated the in vivo value (70 $\pm 7.6 \%)$ whereas for the guinea pig the in vitro test (51 $\pm 3.0 \%)$ underestimated the in vivo value $(68 \pm 9.3 \%)$.

Moody et al., (2007) also investigated the effect of freezing skin samples on the dermal bioavailability of six environmental contaminants which included naphthalene and BaP. Using radiolabelled compounds they measured the dermal bioavailability combining together the $\mathrm{BaP}$ in the receptor solution and absorbed in the skin and found that for all compounds apart from BaP that freezing did not have a significant effect on measured values. In a more recent study, another research group (Jacques et al., 2010) used a rather different experimental set up, working with pig ear skin in which skin punches were seeded dermal side down in polycarbonate Transwell ${ }^{\circledR}$ inserts (28 mm inner diameter, with a $23 \mathrm{~mm}$ diameter and $8 \mu \mathrm{m}$ pore size filter) placed in a 6-well plate prefilled with 1.5 
$\mathrm{ml}$ culture medium at $37{ }^{\circ} \mathrm{C}$ in a $5 \% \mathrm{CO}_{2}$ air incubator. The culture medium was Dulbecco's Eagle Modified Medium (DMEM) supplemented with l-glutamine (0.584 $\left.\mathrm{g} \mathrm{l}^{-1}\right)$, streptomycin/penicillin (100 $\left.\mathrm{g} \mathrm{ml}^{-1}\right)$, fungizone $\left(2.5 \mathrm{~g} \mathrm{ml}^{-1}\right)$, gentamycin $\left(50 \mathrm{~g} \mathrm{ml}^{-1}\right)$ and BSA $(4 \%)$. This is equivalent to a miniaturised Franz diffusion cell. They used a $72 \mathrm{~h}$ experiment dosing both fresh and a frozen skin samples with radiolabelled $\mathrm{BaP}$ at 25, 50, 100, 200, 400, 600 and $800 \mathrm{nmol}$, corresponding to 1.51, 3.03, 6.06,12.12, 24.25, 36.39, $48.52 \mu \mathrm{g} \mathrm{cm}^{-2}$, respectively), applied in $60 \mu \mathrm{l}$ acetone to the skin surface. As well as measuring the distribution of the BaP left on the surface of the skin, absorbed in the skin and in the receptor solution they also quantified the metabolites of $\mathrm{BaP}$ in the receptor solution using Mass Spectrometry and Nuclear Magnetic Resonance analysis. A graphical summary of these results help illustrate the following three important observations (Figure 6):

i. In fresh skin, increasing amounts of the $\mathrm{BaP}$ are metabolised into in the skin and in the receptor solution to such an extent that the parent compound is only a minor fraction of the material collected in the receptor solution.

ii. $\mathrm{BaP}$ is not metabolised in frozen skin, and a larger proportion of $\mathrm{BaP}$ derived material remains in the skin compared to fresh skin. However, the sum of the amount of $\mathrm{BaP}$ in the skin and in the receptor solution was equivalent for both fresh and frozen skin (confirming the results of Moody et al.(2007))

iii. The fraction of the applied dose that is absorbed in the receptor solution decreases for both fresh and frozen skin with increasing applied dose.

Moody et al. (2011) suggest that the reason for very low recovery of $\mathrm{BaP}$ is that it is too insoluble to be partitioned into culture media even if $4 \%$ of BSA was added to the receptor fluid to facilitate the diffusion of lipophilic compounds (Bronaugh et al., 1989; Ng et al., 1992). This also accounts for the very low recoveries of $\mathrm{BaP}$ found in the receptor solutions of the relevant studies outlined (Table 1).

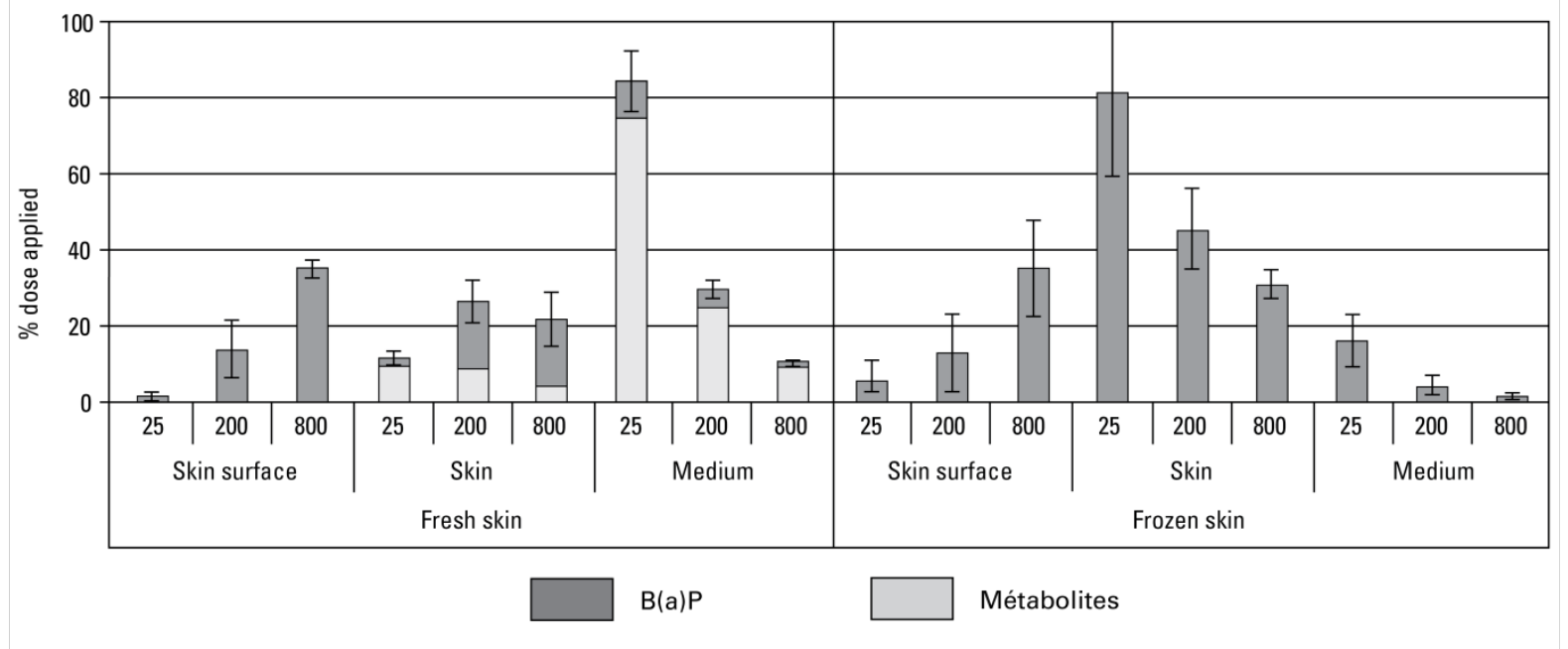


Figure 6 - Percentage of BaP and BaP metabolites present in culture media and skin after $72 \mathrm{~h}$ of incubation under different dosing levels using fresh vs frozen skin explants. Values are expressed as percent of the BaP applied dose and are mean $\pm S D, n=3$. (Jacques et al., 2010).

\subsubsection{Percentage absorbed of applied dose and experimental conditions}

The majority of the work on the dermal bioavailability of PAH has concentrated on BaP, with a smaller amount of information on a few other PAH (Naphthalene: Turkall et al.,, (1994); Phenanthrene: Kadry et al., (1995); USEPA 16: Moody et al., (2011); 60 PAH: Roy et al., (1998)). Roy et al. (1998) measured the dermal bioavailability of 60 PAH using a Franz diffusion cell with rat skin and a Volpo $20{ }^{\mathrm{TM}}$ receptor solution with a $0.01 \%$ thimersol antibacterial agent over a $24 \mathrm{~h}$ period. The results were averaged over 4-5 experiments. The amount of PAH in the receptor solution measured using Gas Chromatography Flame Ionisation Detection (GC/FID) or Gas Chromatography Mass Spectrometry( GC/MS) was used to calculate PADA. This data clearly indicates that increasing $\mathrm{K}_{\mathrm{oc}}$ (i.e. lipophilicity) is associated with a decrease in PADA and is in general agreement with the subsequent findings of Moody et al.(2011). PADA data were then used to develop three QSAR models using $\mathrm{K}_{\mathrm{oc}}$ and other molecular descriptors. $\mathrm{K}_{\mathrm{oc}}$ was found to be the most important predictor in all three models. Although these data have subsequently been used in follow up studies (Shatkin et al., 2007 and Bouwman et al., 2008) care needs to be taken in their use since they were derived only from the amount of PAH found in the receptor solution. It has been clearly shown, however, that significant amounts of PAH are absorbed into the skin (Abdel Rahman, 2002; Roy et al.,, 1998; Roy and Singh, 2001;Wester et al., 1990; Moody et al., 1995; Moody et al., 2007; Moody et al., 2009; Moody et al., 2011; Jacques et al., 2010).

A comparison between PADA and the Log $\mathrm{K}_{\mathrm{oc}}$ for the Roy et al. (1998) study and Moody et al. (2011) data is presented in Figure 7. The Moody et al. (2011) data, which included absorption in the skin is, significantly higher than the Roy et al, (1998) data. Both datasets show the same trend of increasing PADA with decreasing $\log \mathrm{K}_{\mathrm{oc}}$ which can be fitted with linear regression models. Using PADA as the dependant variable and $K_{\mathrm{oc}}$ as the predictor variable, the Roy et al. (1998) data gives a model with a slope of 14.6 and an intercept of 99, explaining $58 \%$ of the variance in the model. The Moody et al.(2011) data gives a slope of -4.7 and intercept of 107 , explaining $55 \%$ of the variance. Confidence intervals for the regression line and for predicting PADA are also presented (Figure 7). Both studies show that the PADA decreases as the hydrophobicity of the PAH increases but also that the inclusion of the PAH absorbed in the skin has significantly increased PADA. 


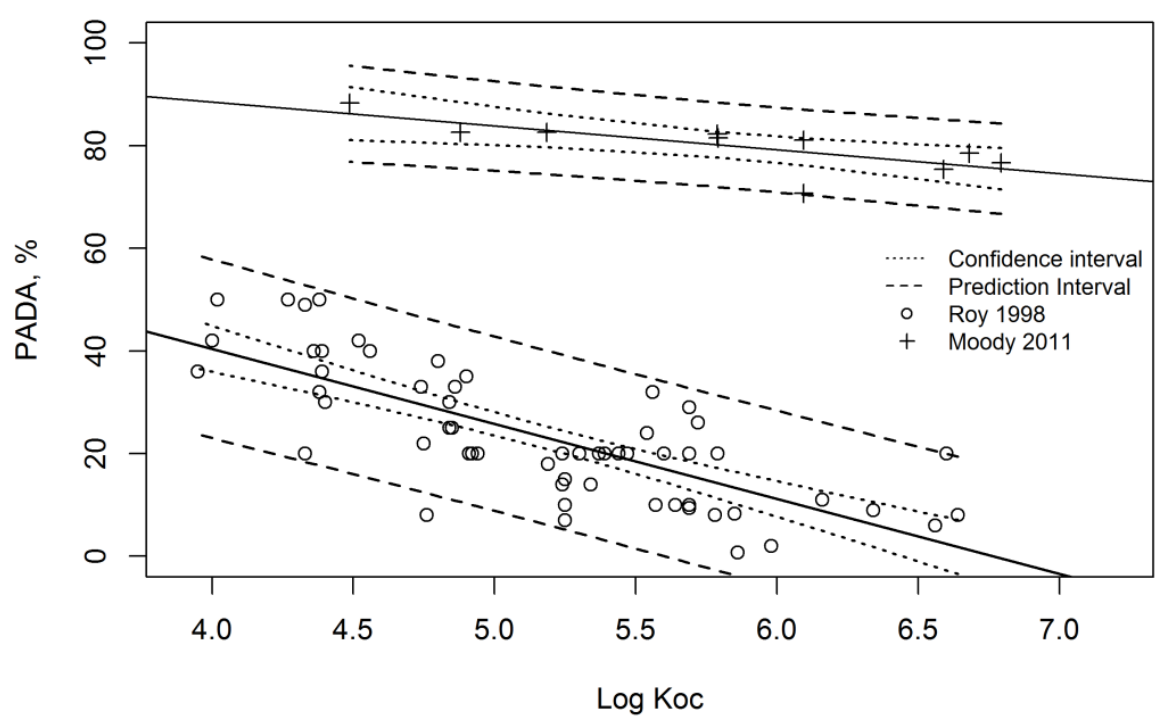

Figure 7 - Measured dermal bioavailability of 60 PAH (Roy et al.,1998b) plotted against log octanol water partition coefficients compared to the study of Moody et al 2011

Whilst there is a lack of consistency in the experimental methods and the way in which data are reported, there are a number of studies which give measured values for dermal bioavailability of PAH in soils. The majority of these data relate to BaP. The data from the summary of information of Spalt et al., (2009) contains 44 measurements of percentage of dose absorbed and associated flux rates through the skin for BaP in a soils matrix. These data are derived from 7 references and represent 15 different soils. In some instances data for the same soil has been reported more than once under different experimental conditions (e.g. different sample contact times or different ageing times for soils). The data from Moody et al. (2007) has been added to this to give a further 2 measurements. All of the data comes from spiked soils and not from naturally aged contamination. 
(a)

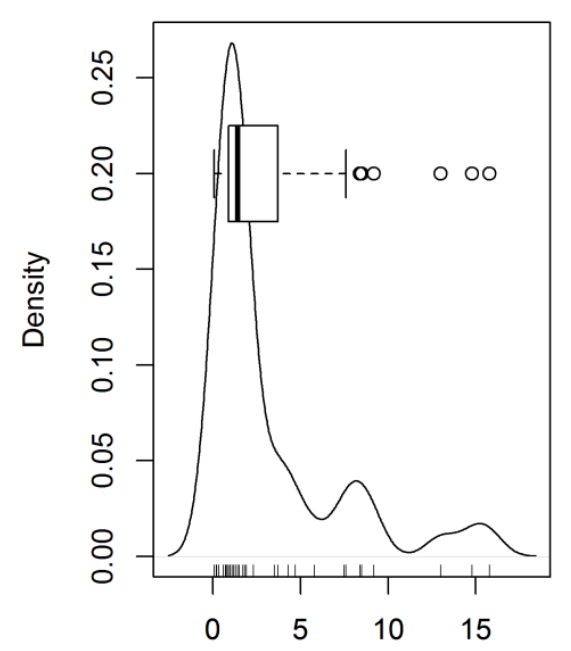

Percentage Dose absorbed (b)

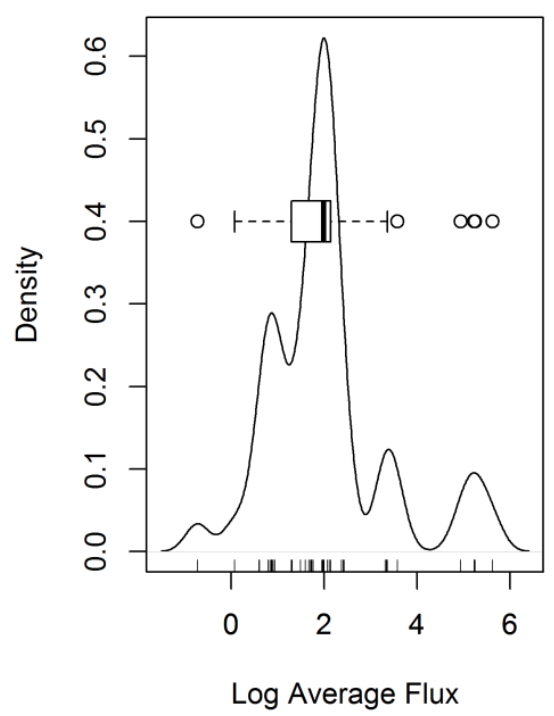

Figure 8 - Summary plots of literature reported BaP dermal bioavailability: (a) the percentage of the dose absorbed; and (b) the average flux of BaP absorbed into the skin.

Summaries of PADA as a density plot overlaid with a box and whisker plot and individual values shown as a tick marks on the $\mathrm{x}$-axis are presented (Figure 8). This shows a range of values from ca. 0 $15 \%$ with a median value of $1.4 \%$. Spalt et al. (2009) suggests that PADA is not always the best way to report the data since it is dependent on the loading rate and time of the experiment and that the uptake flux of the contaminant is more useful, measured in mass of contaminant per unit area per unit time (e.g. $\mathrm{pg} \mathrm{cm}^{-2} \mathrm{~h}^{-1}$ ). The flux of BaP in soil is presented on a log10 scale for comparison (Figure 8). This shows that values cover 6 orders of magnitude with a median value of $100 \mathrm{pg} \mathrm{cm}^{-2} \mathrm{~h}^{-1}$. The one study that measures the dermal bioavailability of PAH from a naturally aged soil (Moody et al., 2011) does not report a value for BaP. Using a linear regression fit to their plot of PAH PADA vs Log $\mathrm{K}_{\mathrm{oc}}$ (Figure 7) the predicted PADA for $\mathrm{BaP}$ in the soil used is $44 \%$ (assuming Log Koc $=5.25$ (Roy et al.,, 1998)), which is over double the highest value found in these other studies (Figure 8). The wide range of values reported clearly indicates that further work is required to understand which are the most important parameters controlling the dermal bioavailability process and, in particular, the effect of soil properties which has to a large extent been overlooked in current work. The range of experimental conditions that have been used are presented (Figure 9) in addition to BaP PADA (Figure 8). 

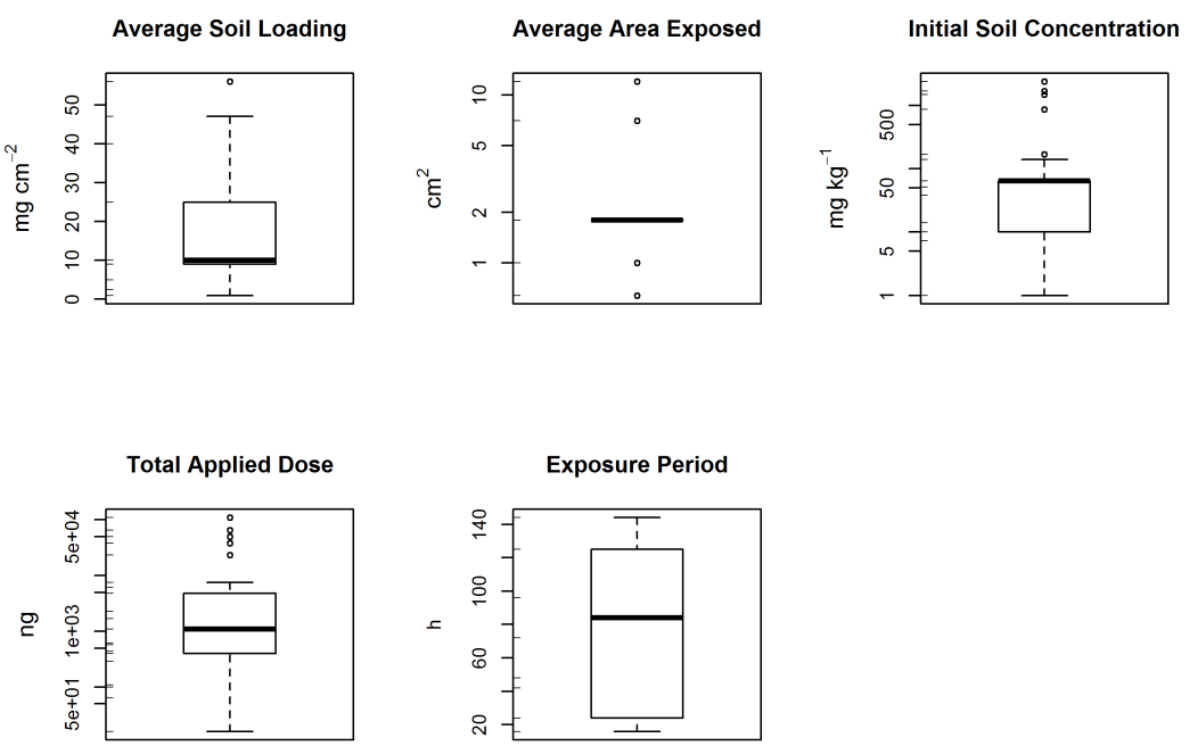

Figure 9 - Boxplot summaries of the experimental conditions used in the 46 literature studies reporting the dermal bioavailability of BaP from Soil (actual data points indicated by tick marks on the y axis)

\subsection{In silico dermal bioavailability methods}

In silico modelling of dermal bioavailability is the establishment of a computer simulation of the amount of chemical compound absorbed into the skin following exposure in any associated vehicle. The simulation can use a combination of input information including physical and chemical properties of the chemical compound and the vehicle being studied along with physical laws governing the diffusivity of a compound through a target media (e.g. Equations 1 to 5). The model can be theoretical where a series of linked mathematical equations are used to describe the underlying theory of all of the processes involved. Alternatively, an empirical model can be used in which the input parameters are the available data related to the chemical compounds, the vehicle and the skin and a regression of various different forms is used to set up a predictive relationship. Models of dermal bioavailability are always simplifications of a highly complex set of biological and physico-chemical interactions that drive passive diffusion of organic compounds from a heterogeneous matrix to a heterogeneous medium i.e. movement from soil to skin. The two approaches to modelling dermal bioavailability found in the literature are Quantitative Structure Activity Relationships (QSAR) and Physiologically-Based Pharmacokinetic (PBPK) models. Relevant examples of both type of study were identified and summarised (Table 2).

The two most common dependent dermal bioavailability variables are: 1) the concentration of compounds present in a given layer of the epidermis following application to the skin (Bioavderm); 2) the ratio of Bioavderm and the total concentration present in the original soil sample ( $\mathrm{ABS}_{\mathrm{d}}$ or PADA) (Equation 1). Other dependent variables include flux, permeability coefficients $\left(\mathrm{K}_{\mathrm{p}}\right)$ or the proportion 
of the total applied concentration in a target organ or tissue (in vivo). Physico-chemical properties commonly include molecular properties (e.g. molecular weight and hydrogen bonding) or partition coefficients (e.g. $\mathrm{K}_{\mathrm{ow}}$ ) for the compound. These properties may be measured or predicted using computer software (e.g. NEMISIS (Oxford Molecular Ltd, 1992)). No studies were found that use the physico-chemical properties of soil, although some recent work on human ingestion bioaccessibility of PAH has started to investigate such relationships using infrared spectroscopy and organic carbon data (Beriro, 2015; Cave et al., 2015).

Numerical predictive models of dermal bioavailability may be produced using stochastic (having a random probability distribution or pattern that may be analysed statistically but may not be predicted precisely) or deterministic (whose resulting behaviour is entirely determined by its initial state and inputs, and which is not random or stochastic) methods. Deterministic methods are either parametric or non-parametric and output the same results each time they are applied. Parametric methods make assumptions about the characteristics of the data or the format of the model. Non-parametric make fewer assumptions about the form input data and modelling process. Multiple linear regression (MLR) (Kirkwood and Sterne, 2003) is the most common parametric method used for estimating dermal bioavailability (Table 2). 
Table 2 - Key in silico dermal bioavailability studies

\begin{tabular}{|c|c|c|c|c|}
\hline Study & Method & Descriptive variables & Analytes and media & Predicted variable \\
\hline \multicolumn{5}{|l|}{ QSAR } \\
\hline Potts \& Guy (1992)* & MLR & $\mathrm{K}_{\mathrm{ow}}$ and molecular weight & 177 pure organic compounds & $\begin{array}{l}\text { Permeability coefficient (Log } \\
\left.\mathrm{K}_{\mathrm{p}}\right)\end{array}$ \\
\hline Barrett et al., (1995) & MLR & Molecular volume, Log Kow and melting point & 91 pure organic compounds & Permeability coefficient $\left(\mathrm{K}_{\mathrm{p}}\right)$ \\
\hline Roy et al., (1998) & MLR & 50 physico-chemical properties & 60 pure $\mathrm{PAH}$ compounds & PADA (in vitro - rat skin) \\
\hline Pugh et al., $(2000)^{* * *}$ & $\begin{array}{l}\text { Principal Components } \\
\text { Analysis and MLR }\end{array}$ & Eigenvectors, molecular weight and $\log K_{p}$, & 57 pure organic compounds & $\begin{array}{l}\text { Flux as Log diffusion (D) } \\
\text { coefficient / path length (h) } \\
(\log (\mathrm{D} / \mathrm{h}))\end{array}$ \\
\hline Devillers (2000) & $\begin{array}{l}\text { Artificial neural } \\
\text { networks }\end{array}$ & Used data from Flynn 1990 and Potts Guy 1992 & $\begin{array}{l}\text { Used pure compound data from Flynn } \\
1990 \text { and Potts Guy } 1992\end{array}$ & $\begin{array}{l}\text { Used data from Flynn } 1990 \text { and } \\
\text { Potts Guy } 1992\end{array}$ \\
\hline Pannier (2003) & $\begin{array}{l}\text { Adaptive neuro fuzzy } \\
\text { inference system }\end{array}$ & $\begin{array}{l}\text { MW and log octanol/water partition coefficients, } \\
\text { hydrogen bond donor activity, hydrogen-bond } \\
\text { acidity, hydrogen bond acceptor activity, } \\
\text { dipolarity/polarizability and the molar } \\
\text { refractivity. }\end{array}$ & $\begin{array}{l}\text { Used pure compound data from Flynn } \\
1990 \text { and Potts Guy } 1992\end{array}$ & $\begin{array}{l}\text { log skin permeability } \\
\text { coefficient (log Kp) }\end{array}$ \\
\hline Riviere \& Brooks (2005) & $\begin{array}{l}\text { Abraham’s Linear Free } \\
\text { Energy Relationship } \\
\text { model }\end{array}$ & $\begin{array}{l}5 \text { physico-chemical properties and } 24 \text { vehicle } \\
\text { combinations }\end{array}$ & $\begin{array}{l}12 \text { organic compounds in ethanol, } \\
\text { propylene glycol Methyl nicotinate and } \\
\text { sodium lauryl sulfate }\end{array}$ & $\begin{array}{l}\text { Permeability constant }\left(\mathrm{K}_{\mathrm{p}}\right) \text { (in } \\
\text { vitro - pig skin) }\end{array}$ \\
\hline Wang et al., (2008) ${ }^{* * * *}$ & $\begin{array}{l}\text { Gene Expression } \\
\text { Programming }\end{array}$ & Range molecular descriptors (number not known) & 60 pure PAH compounds & PADA (in vitro) \\
\hline Moss et al., (2009) ${ }^{* * * * *}$ & Gaussian process & 6 physico-chemical properties & 142 pure organic compounds & $\log K_{p}$ \\
\hline Buist et al., (2010) & $\begin{array}{l}8 \text { literature QSAR } \\
\text { models }\end{array}$ & Molecular weight and Log $\mathrm{K}_{\mathrm{ow}}$ & $\begin{array}{l}15 \text { organic pharmaceutical / cosmetic } \\
\text { compounds (finite dose) }\end{array}$ & $\mathrm{K}_{\mathrm{p}}$ \\
\hline PBPK & & & & \\
\hline
\end{tabular}




\begin{tabular}{|c|c|c|c|c|}
\hline $\begin{array}{l}\text { Kissel \& McAvoy } \\
(1989)^{++}\end{array}$ & $\begin{array}{l}\text { Fugacity based model } \\
\text { (Paterson and Mackay, } \\
1986 \text { ) }\end{array}$ & Physico-chemical properties of soil and skin & $\begin{array}{l}\text { 2,3,7,8-Tetrachlorodibenzodioxin } \\
\text { (TCDD) in soil }\end{array}$ & PADA (in vivo) \\
\hline Wester et al., (2002) & $\begin{array}{l}\text { PBPK (Ramsey and } \\
\text { Andersen, 1984) }\end{array}$ & Partition coefficients and metabolism rates & Perchloroethene in soil & $\mathrm{K}_{\mathrm{p}}$ \\
\hline Shatkin et al., (2002) ${ }^{+}$ & $\begin{array}{l}\text { Fugacity kinetics } \\
\text { (McKone and Howd, } \\
\text { 1992) }\end{array}$ & Physico-chemical properties of soil and skin & $\mathrm{BaP}$ in soil & PADA (in vitro) \\
\hline $\begin{array}{l}\text { Jongeneelen \& Berge } \\
\text { (2012) }\end{array}$ & $\begin{array}{l}\text { PBPK IndusChemFate } \\
\text { (Long-Range Research } \\
\text { Institute, 2015) }\end{array}$ & $\begin{array}{l}\text { Physico-chemical properties for inhalation and } \\
\text { dermal exposure }\end{array}$ & Pyrene vapour & $\begin{array}{l}\text { Urinary concentrations (human } \\
\text { biomonitoring) }\end{array}$ \\
\hline Ortiz et al. (2014) & $\begin{array}{l}\text { human PBPK model } \\
\text { extrapolated } \\
\text { from a rat PBPK model }\end{array}$ & $\begin{array}{l}\text { Physico-chemical properties for mainly dermal } \\
\text { exposure }\end{array}$ & 3-OHBaP & Numerous biological endpoints. \\
\hline
\end{tabular}

Data from Flynn (1990) Scheuplein \& Blank and Ackermann et al

Data from Flynn (1990)

Data from Wilschut et al.,(1995), Degim et al., (1998), Pugh et al., (1996), Abraham (1993) and Abraham et al., (1995)

Data from Roy et al., (1998)

Data from Flynn (1990) and Moss et al (2006)

Data from Roy et al., 1998b and Reeves et al., (2001)

Data from Poiger and Schlatter (1980) 


\subsubsection{Quantitative structure activity relationships}

QSAR (also referred to as quantitative structure permeability relationships (QSPR) and quantitative structure permeability relationships (QSPeR)) for dermal bioavailability statistically relate physicochemical properties to experimentally determined percutaneous penetration of exogenous chemicals (Moss et al., 2002a). These properties relate to the partitioning behaviour of a compound (e.g. $\mathrm{K}_{\text {ow }}$ ) or linear-free energy relationships (LFER) (e.g. molecular size, hydrogen bonding) (Riviere and Brooks, 2005). The first MLR QSAR study applied was applied to pharmaceuticals and toxicology by Potts and Guy (1992) (Equation 6).

$$
\log K_{p}=0.71 \log K_{\text {ow }}-0.0061 M W-6.3
$$

Equation 5 - Potts and Guy Log $K_{p}$ regression model

Most QSAR studies use MLR to link PADA (e.g. Roy et al.,, 1998a) and $\mathrm{K}_{\mathrm{p}}$ (Potts and Guy, 1992) with physico-chemical properties of multiple compounds (Table 2). A large amount of work on QSAR is driven by the need to help characterise the risk to human health under relevant state regulations (e.g. European Commission Council Regulation, 2007). Some QSAR studies have also incorporated principle component analysis (PCA) methods to assist with identifying key controls on dermal bioavailability (Pugh et al., 2000).

Machine learning algorithms are also applied in QSAR, as shown in recent studies: gene expression programming (Wang et al.,, 2008); Gaussian profile (Moss et al.,, 2009) and similar stochastic techniques by others (Table 2).

Cronin and Schultz (2003) recognised that QSAR outputs should achieve the following criteria: 1) a well-defined and measurable endpoint; 2) use a chemically and biologically diverse dataset; 3) be based on chemical descriptors that are consistent with the endpoint; 4) use appropriate statistical methods; and 5) have a strong mechanistic basis. QSAR are usually completed for multiple compounds modelled in a pure form and infinite dose conditions. For example, Roy et al., (1998a) modelled in vivo PADA data for 60 PAH individual compounds whilst Flynn (1990) modelled $\mathrm{K}_{\mathrm{p}}$ for 97 organic chemicals. Studies have since been completed that have used Roy’s and Flynn's data (e.g. Potts and Guy, 1992; Barratt, 1995). Remodelling such data is common because obtaining in vivo and in vitro estimates of dermal bioavailability is time consuming, expensive and can raise important ethical issues.

QSAR studies can be performed for complex vehicles containing the compound although this is much less common than modelling the permeability of pure compounds. Riviere and Brooks (2007) propose 
the use of a hybrid LFER model that incorporates a mixture factor (MF) to account for the physicochemical properties of the vehicle affecting the release of the compound prior to absorption. The hybrid model appears to appropriately account for the variance in the model, providing a useful approach to conducting QSAR for compounds contained in complex vehicles. Many studies now acknowledge the role of the vehicle and the susceptibility of compound to mixture interaction in dermal bioavailability. A review of such work is presented by Karadzovska et al., (2013a). It should be noted that none of the studies mention the effect of soil or focus on PAH.

\subsubsection{Physiologically-based pharmacokinetic models}

PBPK modelling uses mathematical models to describe the absorption, distribution, metabolism and elimination kinetics of different chemical compounds (Dancik et al., 2008). PBPK models of dermal bioavailability assume that the stratum corneum is the principal barrier to permeation and penetration (Dancik et al., 2008). Such models are sometimes referred to as physiologically-based toxicokinetic (PBTK) models (Jongeneelen and Ten Berge, 2012). PBPK models are a unified model of many kinetic equations (e.g. Fick's Laws) for different animal compartments (e.g. epidermis, dermis, blood plasma) that are used to estimate the fate and transport of chemical compounds for a variety of biological endpoints (e.g. adipose tissue, urine, liver). Because of the complexity of such modelling, much of the work is completed using proprietary commercial software (e.g. ADMET Predictor ${ }^{\mathrm{TM}}$ : Simulations Plus Inc. (2015)) or freeware (e.g. IndusTox: Berge and Jongeneelen (2015)). It is necessary to provide the software with physico-chemical properties of the chemicals being modelled. This information is often provided using an embedded QSAR model. As with QSAR this information may be passed to the software using MLR or stochastic techniques.

\section{Estimating dermal bioavailability of PAH in soil}

This review has presented a large amount of information to facilitate an understanding of the estimation of human dermal bioavailability. The aim of this review was to move closer toward developing an integrated in vitro and in silico method for the measurement and modelling of the human dermal bioavailability of PAH in soil. The limitations identified in the literature reviewed have been used to inform the key considerations discussed in the following sections. These are considerations that should be made when developing a suitable physiologically based method for estimating the bioavailability of PAH in soil.

\subsection{Soil dosing}

The importance of the amount of soil applied per unit area as well as considering whether the soil is saturated with the chemical under study have been highlighted (Kissel et al., 2008; Spalt et al., 2009). If the soil is fully saturated then the measurement is more closely aligned to measuring the dermal absorption of the free chemical in the form of an infinite dose and may fail to provide information on 
the effect of soil. Kissel et al. (2008) and Spalt et al. (2009) point out that PADA was dependant on the amount of soil applied per unit area and that if multiple layers of soil are applied to the skin surface then the PADA decreases since the soil layers not touching the skin will supply less of the contaminant to the skin surface. This has been demonstrated or discussed in a number of studies (Kissel et al., 2008; Spalt et al., 2009; Frasch et al., 2014) as well as specifically for BaP in soils (Roy and Singh, 2001). Spalt et al. (2009) provide an equation for loading a monolayer of soil (Equation 7).

$$
S L_{\text {monolayer }}=\rho_{\text {particle }}\left(\frac{\pi d}{6}\right)
$$

Where: SLmonolayer is the soil load $\left(\mathrm{mg} \mathrm{cm}^{-2}\right)$ representing a monolayer, $\rho_{\text {particle }}$ is the particle density of the soil $\left(\mathrm{mg} \mathrm{cm}^{-3}\right)$, and $d$ is the particle diameter $(\mathrm{cm})$.

Equation 6 - Formula to calculate a soil monolayer

This equation makes the assumption of soil particles being spherical in a homogeneous close packed layer. This guidance was used in the Yang et al. (1989) study of in vitro BaP dermal bioavailability on rat skin with a loading rate of $9 \mathrm{mg} \mathrm{cm}^{-2}$. Choate et al. (2006) report literature values for loading rate vary from 0.62 to $1.14 \mathrm{mg} \mathrm{cm}^{-1}$. In practice the assumptions used in the literature studies are completely true to life because of the random nature of human activities and, although equations for corrections of multiple layer loading have been suggested (Kissel et al., 2008; Spalt et al., 2009), the best approach is to use Equation 7 as a guideline and to carry out the absorption experiments at a series of soil loadings to provide information on how this affects the specific contaminant and soil type.

The literature on loading rate relies on the selection of an appropriate soil particle size. This is an important aspect in the design of any dermal bioavailability study involving soil. A recent comprehensive review of literature to select an appropriate particle size for oral bioaccessibility studies is also relevant to quantifying dermal bioavailability (Ruby and Lowney 2012). Both science areas rely on understanding which size fraction is most likely to adhere to human hands. To this end, Ruby and Lowney recommend $<150 \mu \mathrm{m}$. This value differs from other dermal exposure studies i.e. Choate et al (2006), who suggest using $\leq 3 \mu \mathrm{m}$. Both values are considerably lower than $250 \mu \mathrm{m}$, which is currently the most commonly used particle size for oral bioaccessibility.

It has been shown that the exposure times for the different studies vary considerably from $<20 \mathrm{~h}$ to $>140$ h (Figure 8). In addition to the total exposure time, some studies take multiple intermediate measurements (Yang et al., 1989; Turkall et al., 1994; Roy et al,, 1998b; Roy and Singh, 2001; Abdel-Rahman et al., 2002; Moody et al., 2011), whilst others make a single measurement at the end time of the experiment (Wester et al., 1990; Moody et al., 2007). There does not appear to be any standardised approach to make the measurement at specific end-point i.e. when steady state is reached (in the case of infinite dose) or in the case of a flow through diffusion cell when the receptor solution 
concentrations returns to baseline concentration of the chemical being studied (in the case of finite dose). Spalt et al. (2009) suggest that multiple exposure times should be measured to give information on the kinetics of the dermal absorption ranging from $1-2 \mathrm{~h}$ to $>8 \mathrm{~h}$ to characterise the effect more clearly.

\subsection{Soil maturity}

Soil ageing has been shown to have a significant effect on the dermal bioavailability of PAH from soil (Roy and Singh, 2001; Abdel-Rahman et al., 2002). Both studies found that soil ageing reduced the absorption by a factor of 2 compared to freshly spiked soil. This is very much in-line with wider studies on PAH sorption to soils, which also clearly shows how ageing of soils reduces the bioavailability of PAH e.g. Alexander (2000). Most of the studies reviewed do not use naturally aged soil, but rather spike natural soil or amended soil (Yang et al., 1989; Wester et al., 1990; Turkall et al,, 1994; Kadry et al., 1995; Roy et al,, 1998b; Roy and Singh, 2001; Abdel-Rahman et al., 2002; Moody et al., 2007). Part of the reason for this is coupled with using radiolabelled PAH and associated scintillation methods for quantification (Table 1). In order to produce a method that is suitable for risk based land mangement, naturally aged soils covering a range of geological, industrial and contaminant conditions need to be examined. It is clear that soil properties, including aging, play an important part in the sorption and release of PAH from soil (Pignatello and Xing, 1996; Semple et al., 2004; Juhasz et al., 2008; Siciliano et al., 2010; James et al., 2011; Mayer et al., 2011; Delannoy et al., 2014).

\subsection{Skin type}

The effects of different skin types and skin preparation on dermal bioavailability of BaP have been investigated and have been shown to be important (Moody et al., 1995; Moody et al., 2007; Jacques et al., 2010). Skin preparation techniques have also been suggested as source of uncertainty e.g.washing ex vivo skin may affect the role of the lipophilic acid mantle present on the outer epidermis (Chilcotte, 2008). High throughput methods are expected to benefit from use of a synthetic skin (Netzlaff et al., 2005; Schreiber et al., 2005; Schaefer-Korting et al., 2008; Sinko et al,, 2012; Karadzovska and Riviere, 2013b; Uchida et al., 2015) rather than ex vivo skins. However, no examples of their use for $\mathrm{PAH}$ in soils were found in the literature.

\subsection{Experimental design}

Another important point that comes from the reviewed diffusion cell studies, is that the skin membrane usually contains a higher proportion of $\mathrm{BaP}$ at the end of the experiment than the receptor fluid (Wester et al.,, 1990; Roy et al., 1998b; Abdel-Rahman et al., 2002; Moody et al., 2007; Jacques et al., 2010; Moody et al., 2011). Whilst the BaP in the skin has not reached the systemic circulation it has been absorbed into the body and may be leached out slowly at a later date or cause localised health effects in the skin itself. It is clear, therefore, that only measuring the PAH in the receptor 
solution could seriously underestimate the dermal absorption and that any testing protocol must make sure that both the PAH content of both the skin and the receptor solution should be taken into account when calculating the dermal absorption. This approach should also be complemented by an examination of the effect of different receptor solutions, which is not addressed in current literature. For lipophilic compounds such as $\mathrm{PAH}$, the relative solubility of the compound in the receptor solution is likely to be an important driving force of the diffusion gradient through the skin (Jacques et al., 2010). This raises the question of whether receptor solutions are actually necessary if it is simply the amount of PAH that is released from soil into the skin that the most important factor based on the definition dermal bioavailability presented in the introduction of the present study.

Yang et al. (1989) and Moody et al. (1995) provide two examples where the in vitro / in vivo comparisons have been carried out. Yang et al. (1989) used a rat model with a BaP spiked soil and found that, within the uncertainty of the measurements, the measured dermal absorption was the same. Moody et al.(1995) used a rat and a guinea pig model with $\mathrm{BaP}$ in the form of a pure compound and found that the rat in vitro test (PADA 95 $\pm 9.6 \%$ ) overestimated the in vivo value (PADA 70 $\pm 7.6 \%$ )

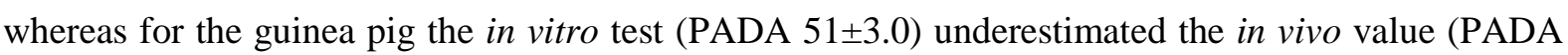
$68 \pm 9.3$ ). Outside of these specific studies on PAH, the general opinion, that is supported by a number of studies (Kielhorn et al., 2006), is that in vitro testing using diffusion cells and ex vivo human and animal skins are acceptable alternatives to in vivo testing. Along with studies using synthetic skin (Karadzovska and Riviere, 2013b), developments in high throughput methods (Sinko et al., 2012), new methodologies (Riviere et al., 2007; Baynes et al., 2008; Karadzovska and Riviere, 2013a) and research into in vitro methods is moving into a new era of development. In particular attention should be paid to the use of synthetic membranes (e.g. Netzlaff et al., 2005; Schreiber et al., 2005; Schaefer-Korting et al., 2008) and new methods such as membrane coated fibres (e.g. Riviere et al., 2007; Baynes et al., 2008; Karadzovska and Riviere, 2013a), since they may offer suitably expedient accurate alternatives to more traditional methods. To date, no studies have been performed for soil borne PAH using these methods.

\subsection{In silico modelling of dermal bioavailability}

Rapid low cost prediction of the dermal bioavailability of organic compounds using in silico methods has received much attention over the past 20 years (Figure 2). The literature shows that physicochemical properties, partition coefficients and diffusion kinetics can be used to produce predictive models to complement in vivo and in vitro estimates (Table 2). The two types of model that appear in the literature are QSAR and PBPK. In silico modelling studies tend to assume an infinite dose scenario, mainly because the permeability coefficient $\left(\mathrm{K}_{\mathrm{p}}\right)$ assumes steady-state conditions and many studies used this as the predicted variable (Table 2). $K_{p}$ is not directly related to the finite dose (Bouwman et al., 2008), which is important because the use of the dermal bioavailability for PAH in 
soil in human health risk assessment of contaminants in soil assumes a finite dose (Environment Agency, 2009b). Buist et al. (2010) used pharmaceutical and cosmetic compounds to produce QSAR models for non-volatile organic compounds for finite dose conditions. No in silico studies were found to examine environmental exposure to finite doses of exogenous organic compounds, either in their pure form or in soil. Riviere and Brooks (2005) propose a mixture factor approach to QSAR modelling of finite doses although their work is based on homogeneous solvent vehicles rather than soil. Despite the apparent absence of relevant work on the dermal bioavailability of PAH in soil, there are some recent studies in the human ingestion bioaccessibility literature which account for finite doses, complex heterogeneous vehicles (soil) and contaminants in mixtures (gasworks or coking works soils) (Beriro, 2015; Cave et al., 2015). In each case these studies use machine learning methods to model the release of PAH from soil into simulated gastro-intestinal fluids.

\section{Conclusions}

This study has brought together literature on in vivo, in vitro and in silico methods for PAH dermal bioavailability methods from a wide variety of scientific disciplines including occupational and environmental exposure, medical, pharmaceutical and cosmetic research and associated mathematical modelling.

The current review has identified a variety of in vitro approaches which can and have been applied to measuring dermal bioavailability of $\mathrm{PAH}$ in soils, as well as identifying a number of practical shortcomings if they are to be applied to high throughput laboratory analysis of contaminated soils. These include: i) the need for better analytical protocols for measuring low concentrations of PAH in a variety of sample matrices; ii) a much better understanding of the soil properties and how these control dermal absorption; iii) account for advancements in diffusion cell designs; and iv) the effect of operating parameters such as receptor fluid composition; use of skin membranes and possible substitutes with new materials.

The current review has identified that mathematical modelling of dermal bioavailability is conducted by a combination of QSAR and PBPB methods. These approaches rely on both traditional statistical and kinetic models but also, and more recently, techniques such as machine learning. Future developments for modelling dermal bioavailability of PAH in soil is could follow a traditional statistical method approach or machine learning /alternative non-linear methods which account for the complexities associated with a finite dose, mixtures of contaminants and the heterogeneous nature of soil. 


\section{REFERENCES}

ABDALLAH, M. A. E., PAWAR, G. \& HARRAD, S. 2015. Evaluation of in vitro vs. in vivo methods for assessment of dermal absorption of organic flame retardants: A review. Environment International, 74, 13-22.

ABDEL-RAHMAN, M. S., SKOWRONSKI, G. A. \& TURKALL, R. M. 2002. Assessment of the dermal bioavailability of soil-aged benzo(a)pyrene. Human and Ecological Risk Assessment, 8, 429-441.

ALEXANDER, M. 2000. Aging, Bioavailability, and Overestimation of Risk from Environmental Pollutants. Environmental Science \& Technology, 34, 4259-4265.

ANDERSEN, R. M., COMAN, G., BLICKENSTAFF, N. R. \& MAIBACH, H. I. 2014. Percutaneous absorption from soil. Reviews on Environmental Health, 29, 169-174.

ANISSIMOV, Y. G. 2014. Mathematical models for skin toxicology. Expert Opinion on Drug Metabolism \& Toxicology, 10, 551-560.

ANISSIMOV, Y. G., JEPPS, O. G., DANCIK, Y. \& ROBERTS, M. S. 2013. Mathematical and pharmacokinetic modelling of epidermal and dermal transport processes. Advanced Drug Delivery Reviews, 65, 169-190.

BARBEAU, D., et al. 2015. Occupational exposure to polycyclic aromatic hydrocarbons: relations between atmospheric mixtures, urinary metabolites and sampling times. International Archives of Occupational and Environmental Health.

BARRATT, M. D. 1995. Quantitative structure-activity relationships for skin permeability. Toxicology in Vitro, 9, 27-37.

BAYNES, R. E., XIA, X. R., IRMAN, M. \& RIVIERE, J. E. 2008. Quantification of chemical mixture interactions modulating dermal absorption using a multiple membrane fiber array. Chemical Research in Toxicology, 21, 591-599.

BERGE, W. \& JONGENEELEN, F. 2015. IndusTox [Online]. Available: http://www.industox.nl/Productinformatieblad\%20IndusChemFate.htm [Accessed 27 January 2015.

BERIRO, D. J. 2015. Gene Expression Programming Models of Bioaccessible Benzo[a]pyrene in coking works soils. PhD, University of Nottingham, UK.

BERIRO, D. J., ABRAHART, R. J. \& DIPLOCK, G. 2014. Genetic Programming in GeoComputation (2nd Ed.), CRC Press.

BERIRO, D. J., ABRAHART, R. J. \& NATHANAIL, C. P. 2012. Comments on "Empirical modelling of plate load test moduli of soil via gene expression programming" by Ali Mollahasani, Amir Hossein Alavi and Amir Hossein Gandomi [Computers and Geotechnics 38 (2011) 281-286]. Computers and Geotechnics, 39, 75-78.

BERIRO, D. J., ABRAHART, R. J. \& NATHANAIL, C. P. 2013a. Letter to the Editor on "Comparison of genetic programming with neuro-fuzzy systems for predicting short-term water table depth fluctuations" by Jalal Shiri \& Ozgur Kisi [Computers and Geosciences (2011)1692 - 1701]. Computers and Geosciences, Volume 56, 216-220.

BERIRO, D. J., ABRAHART, R. J., NATHANAIL, C. P., MORENO, J. \& BAWAZIR, A. S. 2013b. A typology of different development and testing options for symbolic regression modelling of measured and calculated datasets. Environmental Modelling and Software, 47, 29-41.

BOS, J. D. \& MEINARDI, M. M. H. M. 2000. The 500 Dalton rule for the skin penetration of chemical compounds and drugs. Experimental Dermatology, 9, 165-169.

BOSETTI, C., BOFFETTA, P. \& LA VECCHIA, C. 2007. Occupational exposures to polycyclic aromatic hydrocarbons, and respiratory and urinary tract cancers: a quantitative review to 2005. Annals of Oncology, 18, 431-446.

BOUWMAN, T., CRONIN, M. T., BESSEMS, J. G. \& VAN DE SANDT, J. J. 2008. Improving the applicability of (Q)SARs for percutaneous penetration in regulatory risk assessment. Hum Exp Toxicol, 27, 269-76.

BRAIN, K. R. \& CHILCOTT, R. P. 2008. Physicochemical properties affecting skin absorption. In: CHILCOTT, R. P. \& PRICE, S. (eds.) Principles and Practice of Skin Toxicology. London, U.K: John Wiley \& Sons Ltd. 
BRINKMANN, J., et al. 2013. Metabolically competent human skin models: Activation and genotoxicity of benzo[a]pyrene. Toxicological Sciences, 131, 351-359.

BRONAUGH, R. L. \& STEWART, R. F. 1984. Methods for in vitro percutaneous absorption studies III: Hydrophobic compounds. Journal of Pharmaceutical Sciences, 73, 1255-1258.

BUIST, H. E., VAN BURGSTEDEN, J. A., FREIDIG, A. P., MAAS, W. J. M. \& VAN DE SANDT, J. J. M. 2010. New in vitro dermal absorption database and the prediction of dermal absorption under finite conditions for risk assessment purposes. Regulatory Toxicology and Pharmacology, 57, 200-209.

CAVAlLARI, J. M., OSBORN, L. V., SNAWDER, J. E., KRIECH, A. J., OLSEN, L. D., HERRICK, R. F. \& MCCLEAN, M. D. 2012. Predictors of dermal exposures to polycyclic aromatic compounds among hot-mix asphalt paving workers. Ann Occup Hyg, 56, 125-37.

CAVE, M. R., WRAGG, J., DENYS, S., JONDREVILLE, C., AND FEIDT, C. 2011. Oral Bioavailability in Dealing with Contaminated Sites - From Theory towards Practical Application), pages 287-384, Ed Frank Swarjtes. Springer, Netherlands.

CAVE, M. R., VANE, C. H., KIM, A., MOSS-HAYES, V. L., WRAGG, J., RICHARDSON, C. L., HARRISON, H., PAUL NATHANAIL, C., THOMAS, R. \& WILLS, G. 2015. Measurement and modelling of the ingestion bioaccessibility of polyaromatic hydrocarbons in soils. Environmental Technology \& Innovation.

CCME. (CANADIAN COUNCIL OF MINISTERS OF THE ENVIRONMENT). 1999. Canadian Sediment Quality Guidelines for the Protection of Aquatic Life: polycyclic aromatic hydrocarbons (PAHs). Canadian Council of Ministers of the Environment.

CHILCOTT, R. P. 2008. Cutaneous anatomy and function. In: CHILCOTT, R. P. \& PRICE, S. (eds.) Principles and Practice of Skin Toxicology. London, U.K: John Wiley \& Sons Ltd.

CHOATE, L. M., et al. 2006. Dermally Adhered Soil: 1. Amount and particle-size distribution. Integrated Environmental Assessment and Management, 2, 375-384.

CHOOSONG, T., PHAKTHONGSUK, P., TEKASAKUL, S. \& TEKASAKUL, P. 2014. Urinary 1hydroxypyrene levels in workers exposed to polycyclic aromatic hydrocarbon from rubber wood burning. Saf Health Work, 5, 86-90.

CHRISTOPHER, Y., VAN TONGEREN, M., URBANUS, J. \& CHERRIE, J. W. 2011. An assessment of dermal exposure to heavy fuel oil (HFO) in occupational settings. Ann Occup Hyg, 55, 319-28.

CL:AIRE. (CONTAMINATED LAND: APPLICATIONS IN REAL ENVIRONMENTS). 2013. SP1010 - Development of Category 4 Screening Levels for Assessment of Land Affected by Contamination. London UK: DEFRA.

COLlinS, C. D., ALCEGA-GARCIA, S., CRAGGS, M., KADEMOGLOU, K. \& LOWE, S. Accepted. Towards a unified approach for the determination of the bioaccessibility of organic pollutants. Environment International.

COUTO, A., FERNANDES, R., CORDEIRO, M. N. S., REIS, S. S., RIBEIRO, R. T. \& PESSOA, A. M. 2014. Dermic diffusion and stratum corneum: A state of the art review of mathematical models. Journal of Controlled Release, 177, 74-83.

CRANK, J. 1975. The Mathematics of Diffussion, London, Oxford University Press.

CREASER, C. S., WOOD, M. D., ALCOCK, R., COPPLESTONE, D. \& CROOK, P. J. 2007. UK Soil and Herbage Pollutant Survey: UKSHS Report No. 8 Environmental concentrations of polychlorinated biphenyls (PCBs) in UK soil and herbage. Bristol England: Environment Agency,.

CRONIN, M. T. D. \& SCHULTZ, T. W. 2003. Pitfalls in QSAR. Journal of Molecular Structure: THEOCHEM, 622, 39-51.

DANCIK, Y., JEPPS, O. J. \& ROBERTS, M. S. 2008. Phsyiologically Based Pharmacokinetics and Pharmacodynamics of Skin. In: ROBERTS, S. R. \& WALTERS, K. A. (eds.) Dermal Absorption and Toxicity Assessment 2nd ed. New York, U.S: Informa Healthcare.

DEAN, J. R. \& MA, R. 2007. Approaches to assess the oral bioaccessibility of persistent organic pollutants: A critical review. Chemosphere, 68, 1399-1407.

DEFRA. (DEPARTMENT FOR ENVIRONMENT FOOD AND RURAL AFFAIRS). 2012. Environmental Protection Act 1990: Part 2A Contaminated Land Statutory Guidance. Department for Environment Food and Rural Affairs, London. 
DEGIM, I. T. 2006. New tools and approaches for predicting skin permeability. Drug Discovery Today, 11, 517-523.

DELANNOY, M., RYCHEN, G., FOURNIER, A., JONDREVILLE, C. \& FEIDT, C. 2014. Effects of condensed organic matter on PCBs bioavailability in juvenile swine, an animal model for young children. Chemosphere, 104, 105-112.

DENYS, S., CABOCHE, J., TACK, K., RYCHEN, G., WRAGG, J., CAVE, M., JONDREVILLE, C. \& FEIDT, C. 2012. In vivo validation of the unified BARGE method to assess the bioaccessibility of arsenic, antimony, cadmium, and lead in soils. Environmental Science and Technology, 46, 6252-6260.

DEPARTMENT FOR COMMUNITIES AND LOCAL GOVERNMENT. (DEPARTMENT FOR COMMUNITIES AND LOCAL GOVERNMENT). 2012. National Planning Policy Framework. London.

DEPARTMENT FOR ENVIRONMENT FOOD AND RURAL AFFAIRS. 2012. Environmental Protection Act 1990: Part 2A. Contaminated Land Statutory Guidance.

DOR, F., JONGENEELEN, F., ZMIROU, D., EMPEREUR-BISSONNET, P., NEDELLEC, V., HAGUENOER, J. M., PERSON, A., FERGUSON, C. \& DAB, W. 2000. Feasibility of assessing dermal exposure to PAHs of workers on gaswork sites - The SOLEX study. Science of the Total Environment, 263, 47-55.

DTZ. 2011. Bioaccessibility Testing of Contaminated Land for Threats to Human Health.

ELIAS, P. M. 1983. Epidermal lipids, barrier function, and desquamation. Journal of Investigative Dermatology, 80, 44s-49s.

ELOVAARA, E., MIKKOLA, J., MAKELA, M., PALDANIUS, B. \& PRIHA, E. 2006. Assessment of soil remediation workers' exposure to polycyclic aromatic hydrocarbons (PAH): biomonitoring of naphthols, phenanthrols, and 1-hydroxypyrene in urine. Toxicol Lett, 162, $158-63$.

ENVIRONMENT AGENCY. 2004. Model Procedures for the Management of Land Contamination, CLR 11. Environment Agency, Bristol, England.

ENVIRONMENT AGENCY. 2008. Compilation of data for priority organic pollutants for derivation of Soil Guideline Values. Science report: SC050021/SR7.

ENVIRONMENT AGENCY. 2009a. CLEA Software (Version 1.06) Handbook. Science report final SC050021/SR4. Environment Agency, Bristol, England.

ENVIRONMENT AGENCY. 2009b. Updated technical background to the CLEA model. Science Report: SC050021/SR3. Environment Agency, Bristol, England.

EUROPEAN COMMISSION COUNCIL REGULATION. 2007. No 1907/2006 of the European Parliment and of the Council of 18 December 2006 concerning the Registration, Evaluation, Authorisation and Restriction of Chemicals (REACH), establishing a European Chemicals Agency, amending Directive 1999/45/EC and repealing Council Regulation (EEC) No 793/93 and Commission Regulation (EC) No 1488/94 as well as Council Directive 76/769/EEC and Commission Directives 91/155/EEC, 93/67/EEC, 93/105/EC and 2000/21/EC.

FARRELL-JONES, J. 2003. Petroleum hydrocarbons and polyaromatic hydrocarbons. In: THOMPSON, C. K. \& NATHANAIL, C. P. (eds.) Chemical Analysis of Contaminated Land. Oxford: Blackwell Publishing.

FENT, K. W., EISENBERG, J., SNAWDER, J., SAMMONS, D., PLEIL, J. D., STIEGEL, M. A., MUELLER, C., HORN, G. P. \& DALTON, J. 2014. Systemic exposure to PAHs and benzene in firefighters suppressing controlled structure fires. Ann Occup Hyg, 58, 830-45.

FLYNN 1990. Physicochemical determinants of skin absorption. In: GERRITY, T. R. \& HENRY, C. J. (eds.) Principles of Route-to-Route Extrapolation for Risk Assessment. New York: Elsevier.

FRANZ, T. J. 1975. PERCUTANEOUS ABSORPTION. ON THE RELEVANCE OF IN VITRO DATA. J Investig Dermatol, 64, 190-195.

FRASCH, H. F., DOTSON, G. S., BUNGE, A. L., CHEN, C. P., CHERRIE, J. W., KASTING, G. B., KISSEL, J. C., SAHMEL, J., SEMPLE, S. \& WILKINSON, S. 2014. Analysis of finite dose dermal absorption data: Implications for dermal exposure assessment. Journal of Exposure Science and Environmental Epidemiology, 24, 65-73. 
HEREDIA-ORTIZ, R., et al. 2013. Understanding the linked kinetics of benzo(a)pyrene and 3hydroxybenzo(a)pyrene biomarker of exposure using physiologically-based pharmacokinetic modelling in rats. Journal of Pharmacokinetics and Pharmacodynamics, 40, 669-682.

HOOKER, P. J. \& NATHANAIL, C. P. 2006. Risk-based characterisation of lead in urban soils. Chemical Geology, 226, 340-351.

HU, J. \& AITKEN, M. D. 2012. Desorption of polycyclic aromatic hydrocarbons from fieldcontaminated soil to a two-dimensional hydrophobic surface before and after bioremediation. Chemosphere, 89, 542-547.

INTERNATIONAL AGENCY FOR RESEARCH ON CANCER. (Y). 2012. IARC Monographs on the evaluation of carcinogenic risk to humans: chemical agents and related occupations (Volume 100 F). Lyon, France: World Health Organisation.

JACQUES, C., PERDU, E., DUPLAN, H., JAMIN, E. L., CANLET, C., DEBRAUWER, L., CRAVEDI, J. P., MAVON, A. \& ZALKO, D. 2010. Disposition and biotransformation of C14-Benzo(a)pyrene in a pig ear skin model: Ex vivo and in vitro approaches. Toxicology Letters, 199, 22-33.

JAKEMAN, A. J., LETCHER, R. A. \& NORTON, J. P. 2006. Ten iterative steps in development and evaluation of environmental models. Environmental Modelling and Software, 21, 602-614.

JAMES, K., PETERS, R. E., LAIRD, B. D., MA, W. K., WICKSTROM, M., STEPHENSON, G. L. \& SICILIANO, S. D. 2011. Human exposure assessment: A case study of $8 \mathrm{PAH}$ contaminated soils using in vitro digestors and the Juvenile swine model. Environmental Science and Technology, 45, 4586-4593.

JOHNSON, J. E. \& KISSEL, J. C. 1996. Prevalence of dermal pathway dominance in risk assessment of contaminated soils: A survey of superfund risk assessments, 1989-1992. Human and Ecological Risk Assessment (HERA), 2, 356-365.

JONES, K. C. \& DE VOOGT, P. 1999. Persistent organic pollutants (POPs): state of the science. Environmental Pollution, 100, 209-221.

JONGENEELEN, F. \& TEN BERGE, W. 2012. Simulation of urinary excretion of 1-hydroxypyrene in various scenarios of exposure to polycyclic aromatic hydrocarbons with a generic, crosschemical predictive PBTK-model. International Archives of Occupational and Environmental Health, 85, 689-702.

JUHASZ, A. L., SMITH, E., WEBER, J., NAIDU, R., REES, M., ROFE, A., KUCHEL, T. \& SANSOM, L. 2008. Effect of soil ageing on in vivo arsenic bioavailability in two dissimilar soils. Chemosphere, 71, 2180-2186.

KADRY, A. M., SKOWRONSKI, G. A., TURKALL, R. M. \& ABDEL-RAHMAN, M. S. 1995. Comparison between oral and dermal bioavailability of soil-adsorbed phenanthrene in female rats. Toxicology Letters, 78, 153-163.

KAMAL, A., et al. 2014. PAH exposure biomarkers are associated with clinico-chemical changes in the brick kiln workers in Pakistan. Science of the Total Environment, 490, 521-527.

KARADZOVSKA, D., BROOKS, J. D., MONTEIRO-RIVIERE, N. A. \& RIVIERE, J. E. 2013a. Predicting skin permeability from complex vehicles. Advanced Drug Delivery Reviews, 65, 265-277.

KARADZOVSKA, D., BROOKS, J. D., MONTEIRO-RIVIERE, N. A. \& RIVIERE, J. E. 2013b. Predicting skin permeability from complex vehicles. Advanced Drug Delivery Reviews, 65, 265-277.

KARADZOVSKA, D. \& RIVIERE, J. 2013a. Assessing vehicle effects on skin absorption of nonvolatile compounds using membrane-coated fiber arrays. Cutaneous and Ocular Toxicology, 32, 283-289.

KARADZOVSKA, D. \& RIVIERE, J. E. 2013b. Assessing vehicle effects on skin absorption using artificial membrane assays. European Journal of Pharmaceutical Sciences, 50, 569-576.

KESKIN, M. E. \& TERZI, O. 2006. Artificial neural network models of daily pan evaporation. ASCE Journal of Hydrologic Engineering, 11, 65-70.

KIELHORN, J., MELCHING-KOLLMUN, S. \& MANGELSDORF, I. 2006. Environmental Health Criteria 235 Dermal Absorption. Geneva, Switzerland: World Health Organisation.

KIRKWOOD, B. R. \& STERNE, J. A. C. 2003. Essential medical statistics (2nd Ed), Oxford, Blackwell. 
KISSEL, J. C., SPALT, E. W., SHIRAI, J. H. \& BUNGE, A. L. 2008. Dermal Absorption of Chemical Contaminants from Soil. Dermal Absorption and Toxicity Assessment, 563-573.

KRIECH, A. J., OSBORN, L. V., SNAWDER, J. E., OLSEN, L. D., HERRICK, R. F., CAVALlARI, J. M., MCCLEAN, M. D. \& BLACKBURN, G. R. 2011. Study Design and Methods to Investigate Inhalation and Dermal Exposure to Polycyclic Aromatic Compounds and Urinary Metabolites from Asphalt Paving Workers: Research Conducted through Partnership. Polycyclic Aromatic Compounds, 31, 243-269.

LONG-RANGE RESEARCH INSTITUTE. 2015. IndusChemFate [Online]. Available: http://ceficlri.org/lri_toolbox/induschemfate/ [Accessed 28 January 2015.

LORENZI, D., ENTWISTLE, J., CAVE, M., WRAGG, J. \& DEAN, J. R. 2012. The application of an in vitro gastrointestinal extraction to assess the oral bioaccessibility of polycyclic aromatic hydrocarbons in soils from a former industrial site. Analytica Chimica Acta, 735, 54-61.

MAYER, P., OLSEN, J. L., GOULIARMOU, V., HASINGER, M., KENDLER, R. \& LOIBNER, A. P. 2011. A contaminant trap as a tool for isolating and measuring the desorption resistant fraction of soil pollutants. Environmental Science and Technology, 45, 2932-2937.

MCCLEAN, M. D., OSBORN, L. V., SNAWDER, J. E., OLSEN, L. D., KRIECH, A. J., SJODIN, A., LI, Z., SMITH, J. P., SAMMONS, D. L., HERRICK, R. F. \& CAVALLARI, J. M. 2012. Using urinary biomarkers of polycyclic aromatic compound exposure to guide exposurereduction strategies among asphalt paving workers. Ann Occup Hyg, 56, 1013-24.

MCKONE, T. E. \& HOWD, R. A. 1992. Estimating dermal uptake of nonionic organic chemicals from water and soil: I. Unified fugacity-based models for risk assessments. Risk Analysis, 12, 543-557.

MICHAELS, A. S., CHANDRASEKARAN, S. K. \& SHAW, J. E. 1975. DRUG PERMEATION THROUGH HUMAN SKIN: THEORY AND IN VITRO EXPERIMENTAL MEASUREMENT. AIChE Journal, 21, 985-996.

MIKI, R., et al. 2015. Development of a membrane impregnated with a poly(dimethylsiloxane)/poly(ethylene glycol) copolymer for a high-throughput screening of the permeability of drugs, cosmetics, and other chemicals across the human skin. European Journal of Pharmaceutical Sciences, 66, 41-49.

MODI, B. G., NEUSTADTER, J., BINDA, E., LEWIS, J., FILLER, R. B., ROBERTS, S. J., KWONG, B. Y., REDDY, S., OVERTON, J. D., GALAN, A., TIGELAAR, R., CAI, L., FU, P., SHLOMCHIK, M., KAPLAN, D. H., HAYDAY, A. \& GIRARDI, M. 2012. Langerhans cells facilitate epithelial DNA damage and squamous cell carcinoma. Science, 335, 104-108.

MOODY, R. P., JONCAS, J., RICHARDSON, M. \& CHU, I. 2007. Contaminated soils (I): In vitro dermal absorption of benzo[a]pyrene in human skin. Journal of Toxicology and Environmental Health - Part A: Current Issues, 70, 1858-1865.

MOODY, R. P., JONCAS, J., RICHARDSON, M., PETROVIC, S. \& CHU, I. 2009. Contaminated soils (II): In vitro dermal absorption of nickel (Ni-63) and mercury (Hg-203) in human skin. Journal of Toxicology and Environmental Health - Part A: Current Issues, 72, 551-559.

MOODY, R. P. \& MAIBACH, H. I. 2006. Skin decontamination: Importance of the wash-in effect. Food Chem Toxicol, 44, 1783-8.

MOODY, R. P., NADEAU, B. \& CHU, I. 1995. In vivo and in vitro dermal absorption of benzo[a]pyrene in rat, guinea pig, human and tissue-cultured skin. Journal of Dermatological Science, 9, 48-58.

MOODY, R. P., TYTCHINO, A. V., YIP, A. \& PETROVIC, S. 2011. A novel "by difference" method for assessing dermal absorption of polycyclic aromatic hydrocarbons from soil at federal contaminated sites. J Toxicol Environ Health A, 74, 1294-303.

MOSS, G. P., DEARDEN, J. C., PATEL, H. \& CRONIN, M. T. D. 2002a. Quantitative structurepermeability relationships (QSPRs) for percutaneous absorption. Toxicology in Vitro, 16, 299317.

MOSS, G. P., DEARDEN, J. C., PATEL, H. \& CRONIN, M. T. D. 2002b. Quantitative structurepermeability relationships (QSPRs) for percutaneous absorption. Toxicology in Vitro, 16, 299317. 
MOSS, G. P., SUN, Y., PRAPOPOULOU, M., DAVEY, N., ADAMS, R., PUGH, W. J. \& BROWN, M. B. 2009. The application of Gaussian processes in the prediction of percutaneous absorption. Journal of Pharmacy and Pharmacology, 61, 1147-1153.

NATHANAIL, C. P. \& MCCAFFREY, C. 2003. The use of oral bioaccessibility in assessment of risks to human health from contaminated land. Land Contamination and Reclamation, 11, 309-313.

NATHANAIL, C. P., et al. 2007. Incorporating bioaccessibility in detailed quantitative human health risk assessments. Journal of Environmental Science and Health - Part A Toxic/Hazardous Substances and Environmental Engineering, 42, 1193-1202.

NATHANAIL, C. P., MCCAFFREY, C., ASHMORE, M., CHENG, Y. Y., GILLET, A., OGDEN, R. \& SCOTT, D. I. 2009. 2nd Edition LQM/CIEH Generic Assessment Criteria for Human Health Risk Assessment. LQM Press, Nottingham.

NATHANAIL, C. P., MCCAFFREY, C., GILLET, A., OGDEN, R. \& NATHANAIL, J. 2014. LQM/CIEH S4ULs for Human Health Risk Assessment. LQM Press, Nottingham.

NATHANAIL, C. P. \& OGDEN, R. C. 2013. Derivation of a site-specific assessment criterion for benzo[a]pyrene in red shale at a former coking works. Journal of Environmental Science and Health - Part A Toxic/Hazardous Substances and Environmental Engineering, 48, 594-603.

NATHANAIL, C. P. \& SMITH, R. 2007. Incorporating bioaccessibility in detailed quantitative human health risk assessments. Journal of Environmental Science and Health - Part A Toxic/Hazardous Substances and Environmental Engineering, 42, 1193-1202.

NATHANAIL, J., BARDOS, P. \& NATHANAIL, P. 2002. Contaminated Land Management: Ready Reference, Nottingham: Land Quality Press.

NETZLAFF, F., LEHR, C. M., WERTZ, P. W. \& SCHAEFER, U. F. 2005. The human epidermis models EpiSkin ${ }^{\circledR}$, SkinEthic ${ }^{\circledR}$ and EpiDerm ${ }^{\circledR}$ : An evaluation of morphology and their suitability for testing phototoxicity, irritancy, corrosivity, and substance transport. European Journal of Pharmaceutics and Biopharmaceutics, 60, 167-178.

OLSEN, L. D., SNAWDER, J. E., KRIECH, A. J. \& OSBORN, L. V. 2011a. Development of a 5Layer Passive Organic Dermal (POD) Sampler. Polycyclic Aromatic Compounds, 31, 154172.

OLSEN, L. D., SNAWDER, J. E., KRIECH, A. J. \& OSBORN, L. V. 2011b. Development of a 5layer passive organic dermal (POD) sampler. Polycyclic Aromatic Compounds, 31, 154-172.

ORGANISATION FOR ECONOMIC CO-OPERATION AND DEVELOPMENT. 2004. OECD Guideline for the testing of chemicals. Skin absorption: in vitro Method. OECD.

ORTIZ, R. H., et al. 2014. Use of physiologically-based pharmacokinetic modeling to simulate the profiles of 3-hydroxybenzo(a)pyrene in workers exposed to polycyclic aromatic hydrocarbons. PLOS ONE, 9.

OSBORN, L. V., SNAWDER, J. E., OLSEN, L. D., KRIECH, A. J., CAVALLARI, J. M., HERRICK, R. F., MCCLEAN, M. D. \& BLACKBURN, G. R. 2011a. Pilot Study for the Investigation of Personal Breathing Zone and Dermal Exposure Using Levels of Polycyclic Aromatic Compounds (PAC) and PAC Metabolites in the Urine of Hot-Mix Asphalt Paving Workers. Polycyclic Aromatic Compounds, 31, 173-200.

OSBORN, L. V., SNAWDER, J. E., OLSEN, L. D., KRIECH, A. J., CAVALLARI, J. M., HERRICK, R. F., MCCLEAN, M. D. \& BLACKBURN, G. R. 2011b. Pilot Study for the Investigation of Personal Breathing Zone and Dermal Exposure Using Levels of Polycyclic Aromatic Compounds (PAC) and PAC Metabolites in the Urine of Hot-Mix Asphalt Paving Workers. Polycyclic Aromatic Compounds, 31, 173-200.

OXFORD MOLECULAR LTD. 1992. Nemesis: Molecular modelling for everyone [Online]. Available: http://nemesis-package.sourceforge.net/ [Accessed 28 January 2015.

PANNATIER, A., JENNER, P., TESTA, B. \& ETTER, J. C. 1978. The skin as a drug-metabolizing organ. Drug Metabolism Reviews, 8, 319-343.

PATERSON, S. \& MACKAY, D. 1986. A pharmacokinetic model of styrene inhalation with the fugacity approach. Toxicology and Applied Pharmacology, 82, 444-453.

PIGNATELLO, J. J. \& XING, B. 1996. Mechanisms of slow sorption of organic chemicals to natural particles. Environmental Science and Technology, 30, 1-11. 
POIGER, H. \& SCHLATTER, C. 1980. Influence of solvents and adsorbents on dermal and intestinal absorption of TCDD. Food and Cosmetics Toxicology, 18, 477-481.

POTTS, R. O. \& GUY, R. H. 1992. Predicting skin permeability. Pharmaceutical Research, 9, 663669.

PUBLIC HEALTH ENGLAND. 2008. Polycyclic aromatic hydrocarbons (Benzo[a]pyrene) Toxicological Overview - Version 1.

PUGH, W. J. \& CHILCOTT, R. P. 2008. Principles of diffusion and thermodynamics. In: CHILCOTT, R. P. \& PRICE, S. (eds.) Principles and Practice of Skin Toxicology. London, U.K: John Wiley \& Sons Ltd.

PUGH, W. J., DEGIM, I. T. \& HADGRAFT, J. 2000. Epidermal permeability-penetrant structure relationships: 4, QSAR of permeant diffusion across human stratum corneum in terms of molecular weight, H-bonding and electronic charge. International Journal of Pharmaceutics, 197, 203-211.

RAMSEY, J. C. \& ANDERSEN, M. E. 1984. A physiologically based description of the inhalation pharmacokinetics of styrene in rats and humans. Toxicology and Applied Pharmacology, 73, 159-175.

RIVIERE, J. E., et al. 1986. The isolated perfused porcine skin flap (IPPSF). I. A novel in vitro model for percutaneous absorption and cutaneous toxicology studies. Fundamental and Applied Toxicology, 7, 444-453.

RIVIERE, J. E., et al. 1999. Dermal absorption and distribution of topically dosed jet fuels Jet-A, JP8, and JP-8(100). Toxicology and applied pharmacology, 160, 60-75.

RIVIERE, J. E., BAYNES, R. E. \& XIA, X.-R. 2007. Membrane-coated fiber array approach for predicting skin permeability of chemical mixtures from different vehicles. Toxicological Sciences, 99, 153-161.

RIVIERE, J. E. \& BROOKS, J. D. 2005. Predicting skin permeability from complex chemical mixtures. Toxicology and Applied Pharmacology, 208, 99-110.

RIVIERE, J. E. \& BROOKS, J. D. 2007. Prediction of dermal absorption from complex chemical mixtures: Incorporation of vehicle effects and interactions into a QSPR framework. SAR and QSAR in Environmental Research, 18, 31-44.

ROBERTS, S. R. \& WALTERS, K. A. 2008. Human Skin Morphology and Dermal Absorption. In: ROBERTS, S. R. \& WALTERS, K. A. (eds.) Dermal Absorption and Toxicity Assessment 2nd ed. New York, U.S: Informa Healthcare.

ROTA, M., BOSETTI, C., BOCCIA, S., BOFFETTA, P. \& LA VECCHIA, C. 2014. Occupational exposures to polycyclic aromatic hydrocarbons and respiratory and urinary tract cancers: an updated systematic review and a meta-analysis to 2014. Archives of Toxicology, 88, 14791490.

ROY, T. A., KRUEGER, A. J., MACKERER, C. R., NEIL, W., ARROYO, A. M. \& YANG, J. J. 1998a. SAR models for estimating the percutaneous absorption of polynuclear aromatic hydrocarbons. SAR and QSAR in environmental research, 9, 171-185.

ROY, T. A., KRUEGER, A. J., TAYLOR, B. B., MAURO, D. M. \& GOLDSTEIN, L. S. 1998b. Studies estimating the dermal bioavailability of polynuclear aromatic hydrocarbons from manufactured gas plant tar-contaminated soils. Environmental Science and Technology, 32, 3113-3117.

ROY, T. A. \& SINGH, R. 2001. Effect of soil loading and soil sequestration on dermal bioavailability of polynuclear aromatic hydrocarbons. Bulletin of Environmental Contamination and Toxicology, 67, 324-331.

RUBY, M. V., and Lowney, L. W. 2012. Selective soil particle adherence to hands: Implications for understanding oral exposure to soil contaminants. Environmental Science and Technology, 46, 12759-12771.

SCHAEFER-KORTING, M., BOCK, U., DIEMBECK, W., DUESING, H.-J., GAMER, A., HALTNER-UKOMADU, E., HOFFMANN, C., KACA, M., KAMP, H., KERSEN, S., KIETZMANN, M., KORTING, H. C., KRAECHTER, H.-U., LEHR, C.-M., LIEBSCH, M., MEHLING, A., MUELLER-GOYMANN, C., NETZLAFF, F., NIEDORF, F., RUEBBELKE, M. K., SCHAEFER, U., SCHMIDT, E., SCHREIBER, S., SPIELMANN, H., VUIA, A. \& WEIMER, M. 2008. The use of reconstructed human epidermis for skin 
absorption testing: results of the validation study. Atla-Alternatives to Laboratory Animals, 36, 161-187.

SCHREIBER, S., MAHMOUD, A., VUIA, A., RUBBELKE, M. K., SCHMIDT, E., SCHALLER, M., KANDAROVA, H., HABERLAND, A., SCHAFER, U. F., BOCK, U., KORTING, H. C., LIEBSCH, M. \& SCHAFER-KORTING, M. 2005. Reconstructed epidermis versus human and animal skin in skin absorption studies. Toxicol In Vitro, 19, 813-22.

SEMPLE, K. T., DOICK, K. J., JONES, K. C., BURAUEL, P., CRAVEN, A. \& HARMS, H. 2004. Defining bioavailability and bioaccessibility of contaminated soil and sediment is complicated. Environmental Science and Technology, 38, 228A-231A.

SERDAR, B., LEE, D. \& DOU, Z. 2012. Biomarkers of exposure to polycyclic aromatic hydrocarbons (PAHs) and DNA damage: a cross-sectional pilot study among roofers in South Florida. BMJ Open, 2.

SHATKIN, J. A., WAGLE, M., KENT, S. \& MENZIE, C. A. 2002. Development of a biokinetic model to evaluate dermal absorption of polycyclic aromatic hydrocarbons from soil. Human and Ecological Risk Assessment, 8, 713-734.

SICILIANO, S. D., LAIRD, B. D. \& LEMIEUX, C. L. 2010. Polycyclic aromatic hydrocarbons are enriched but bioaccessibility reduced in brownfield soils adhered to human hands. Chemosphere, 80, 1101-1108.

SIMULATIONS PLUS INC. 2015. ADMET Predictor [Online]. Available: http://www.simulationsplus.com/Products.aspx?ADMET\%20Predictor\&grpID=1\&cID=10\&pID=13 [Accessed 27 January 2015.

SINKO, B., GARRIGUES, T. M., BALOGH, G. T., NAGY, Z. K., TSINMAN, O., AVDEEF, A. \& TAKACS-NOVAK, K. 2012. Skin-PAMPA: A new method for fast prediction of skin penetration. European Journal of Pharmaceutical Sciences, 45, 698-707.

SMITH, J. P., BIAGINI, R. E., JOHNSON, B. C., OLSEN, L. D., MACKENZIE, B. A., ROBERTSON, S. A., SAMMONS, D. L., STRILEY, C. A. F., WALKER, C. V. \& SNAWDER, J. E. 2011. Assessment of Exposure to PACs in Asphalt Workers: Measurement of Urinary PACs and their Metabolites with an ELISA Kit. Polycyclic Aromatic Compounds, 31, 270-285.

SPALT, E. W., KISSEL, J. C., SHIRAI, J. H. \& BUNGE, A. L. 2009. Dermal absorption of environmental contaminants from soil and sediment: a critical review. J Expo Sci Environ Epidemiol, 19, 119-48.

TRIPP, J. M., KARTONO, F. \& MAIBACH, H. I. 2007. Percutaneous penetration of pesticides: Clinical ramifications. ACS Symposium Series, 951, 35-48.

TSAI, P. J., et al. 2001. Health-risk assessment for workers exposed to polycyclic aromatic hydrocarbons (PAHs) in a carbon black manufacturing industry. Science of the Total Environment, 278, 137-150.

TURKALL, R. M., SKOWRONSKI, G. A., KADRY, A. M. \& ABDEL-RAHMAN, M. S. 1994. A comparative study of the kinetics and bioavailability of pure and soil-adsorbed naphthalene in dermally exposed male rats. Archives of Environmental Contamination and Toxicology, 26, 504-509.

U.N ECONOMIC COMMISSION FOR EUROPE. 1998. Executive Body for the Convention on Long-range Transboundary Air Pollution, Special session, Aarhus, Denmark, 24 June 1998, Item 3 of the provisional agenda. United Nations, Geneva.

U.S ENVIRONMENTAL PROTECTION AGENCY. 2007. Dermal Exposure Assessment: A Summary of EPA Approaches. Washington, DC, US: National Center for Environmental Assessment, Office of Research and Development, U.S. Environmental Protection Agency

U.S ENVIRONMENTAL PROTECTION AGENCY. (Y). 2013. Toxicological(CASRN 50-32-8) Review of Benzo[a]pyrene. In Support of Summary Information on the Integrated Risk Information System (IRIS). Main Report and Supplemental Information. U.S Environmental Protection Agency.

UCHIDA, T., KADHUM, W. R., KANAI, S., TODO, H., OSHIZAKA, T. \& SUGIBAYASHI, K. 2015. Prediction of skin permeation by chemical compounds using the artificial membrane, Strat-M ${ }^{\mathrm{TM}}$. European Journal of Pharmaceutical Sciences, 67, 113-118. 
VAANANEN, V., HAMEILA, M., KALLIOKOSKI, P., NYKYRI, E. \& HEIKKILA, P. 2005. Dermal exposure to polycyclic aromatic hydrocarbons among road pavers. Ann Occup Hyg, 49, 167-78.

VAN DE SANDT, J. J. M., DELLARCO, M. \& VAN HEMMEN, J. J. 2007. From dermal exposure to internal dose. Journal of Exposure Science and Environmental Epidemiology, 17, S38-S47.

VANE, C. H., KIM, A. W., BERIRO, D. J., CAVE, M. R., KNIGHTS, K., MOSS-HAYES, V. \& NATHANAIL, P. C. 2014. Polycyclic aromatic hydrocarbons (PAH) and polychlorinated biphenyls (PCB) in urban soils of Greater London, UK. Applied Geochemistry, 51, 303-314.

WANG, T., SI, H., CHEN, P., ZHANG, K. \& YAO, X. 2008. QSAR models for the dermal penetration of polycyclic aromatic hydrocarbons based on gene expression programming. QSAR and Combinatorial Science, 27, 913-921.

WRAGG, J., et al. 2011. An inter-laboratory trial of the unified BARGE bioaccessibility method for arsenic, cadmium and lead in soil. Science of the Total Environment, 409, 4016-4030.

WESTER, R. C., MAIBACH, H. I., BUCKS, D. A. W., SEDIK, L., MELENDRES, J., LIAO, C. \& DIZIO, S. 1990. Percutaneous absorption of [C]DDT and [C]Benzo[a]pyrene from soil. Toxicological Sciences, 15, 510-516.

YANG, J. J., ROY, T. A., KRUEGER, A. J., NEIL, W. \& MACKERER, C. R. 1989. In vitro and in vivo percutaneous absorption of benzo[a]pyrene from petroleum crude-fortified soil in the rat. Bulletin of Environmental Contamination and Toxicology, 43, 207-214. 